\title{
Review Article Neuroprotection as a Therapeutic Target for
Diabetic Retinopathy
}

\author{
Cristina Hernández, ${ }^{1}$ Massimo Dal Monte, ${ }^{2,3}$ Rafael Simó, ${ }^{1}$ and Giovanni Casini ${ }^{2,3}$ \\ ${ }^{1}$ CIBERDEM (CIBER de Diabetes y Enfermedades Metabolicas Asociadas) and Diabetes and Metabolism Research Unit, \\ Vall d'Hebron Institut de Recerca (VHIR), Universitat Autonoma de Barcelona, Passeig Vall d'Hebron 119-129, 08035 Barcelona, Spain \\ ${ }^{2}$ Department of Biology, University of Pisa, Via San Zeno 31, 56127 Pisa, Italy \\ ${ }^{3}$ Interdepartmental Research Center Nutrafood "Nutraceuticals and Food for Health", University of Pisa, Via del Borghetto 80, \\ 56124 Pisa, Italy
}

Correspondence should be addressed to Cristina Hernández; cristina.hernandez@vhir.org and Giovanni Casini; giovanni.casini@unipi.it

Received 22 December 2015; Revised 29 February 2016; Accepted 16 March 2016

Academic Editor: Ronald G. Tilton

Copyright (C) 2016 Cristina Hernández et al. This is an open access article distributed under the Creative Commons Attribution License, which permits unrestricted use, distribution, and reproduction in any medium, provided the original work is properly cited.

\begin{abstract}
Diabetic retinopathy (DR) is a multifactorial progressive disease of the retina and a leading cause of vision loss. DR has long been regarded as a vascular disorder, although neuronal death and visual impairment appear before vascular lesions, suggesting an important role played by neurodegeneration in DR and the appropriateness of neuroprotective strategies. Upregulation of vascular endothelial growth factor (VEGF), the main target of current therapies, is likely to be one of the first responses to retinal hyperglycemic stress and VEGF may represent an important survival factor in early phases of DR. Of central importance for clinical trials is the detection of retinal neurodegeneration in the clinical setting, and spectral domain optical coherence tomography seems the most indicated technique. Many substances have been tested in animal studies for their neuroprotective properties and for possible use in humans. Perhaps, the most intriguing perspective is the use of endogenous neuroprotective substances or nutraceuticals. Together, the data point to the central role of neurodegeneration in the pathogenesis of DR and indicate neuroprotection as an effective strategy for treating this disease. However, clinical trials to determine not only the effectiveness and safety but also the compliance of a noninvasive route of drug administration are needed.
\end{abstract}

\section{Introduction}

Diabetic retinopathy (DR) is a multifactorial progressive disease of the retina with high social impact and with an extremely complex pathogenesis that involves a variety of different cells, molecules, and factors. Metabolic changes in the diabetic retina result in altered expression pattern of a number of mediators including growth factors, neurotrophic factors, cytokines/chemokines, vasoactive agents, and inflammatory and adhesion molecules, resulting in vascular lesions and cell death [1-4]. In the recent past, DR was generally considered a purely vascular disorder of the retina and visual impairment was attributed to vascular damage. In the last few years it has become evident that considerable damage of retinal neurons is also present in early stages of
DR. As the investigations proceed and data are produced, it appears that neurodegeneration also plays a significant role in microvascular impairment [5-9].

The present review focuses on the possible causes and the effects of neuronal damage in DR and discusses possible approaches based on neuroprotection for the treatment of this disease. In particular, with this review of the literature we invite the reader to consider the following hypotheses: (i) neuronal damage directly induced by diabetic stress may be responsible for functional abnormalities in visual function; (ii) a central role in linking neuronal damage to early microvascular damage (i.e., vascular leakage) may be played by VEGF expressed and released by damaged neurons; (iii) therapeutic strategies based on neuroprotection will be useful in preventing or arresting DR development. 


\section{Neurodegeneration in DR and the Role of VEGF}

2.1. Evidence of Retinal Neuronal Damage in DR. There is evidence that death of neurons appears before that of vascular cells in the retina of both humans with DR and experimental animal models of DR [10], while recent data in $\mathrm{db} / \mathrm{db}$ diabetic mice reported ganglion cell apoptosis, retinal thinning, and ERG deficits in the absence of obvious microvascular changes [11]. These observations support the view that neuronal damage is an early event in the pathogenesis of DR $[12,13]$ and that DR may be considered a neurodegenerative eye disease [14]. Only in a few cases the occurrence of extensive neuronal apoptosis in DR has not been fully acknowledged $[15,16]$ and the only report excluding any loss of retinal ganglion cells in DR is based on an analysis of cell numbers in the GCL of retinal sections [17], which may have been unfit to detect significant changes. Actually, the vast majority of papers document the presence of apoptotic markers and/or the appearance of functional defects in diabetic retinas. In particular, apoptotic markers, including caspase-3 [18, 19], caspase-9 [19], Bax [18, 19], Bad [20], and Fas [18], have been observed to increase in retinal ganglion cells of patients with diabetes, while enhanced release of cytochrome $c$ and expression of apoptosis inducing factor has been documented both in ganglion cells and in photoreceptor cells [20]. Consistent with these findings, optical coherence tomography (OCT) observations in patients with type 1 or type 2 diabetes revealed reduced thickness of the inner retinal layers, which was only minimally associated with vascular lesions [21-23]. Interestingly, a recent work, based on a retrospective analysis of spectral domain OCT (SDOCT) scans of a number of subjects with diabetes and with various stages of DR, shows that thinning of the inner retina appears early in the pathology and before any visible vascular signs of DR can be appreciated [24], suggesting the opportunity of neuroprotective interventions to prevent chronic neurodegeneration. Experimental data in animal models of DR indicate that uncontrolled insulin-deficient diabetes markedly increases neuronal cell death in the retina $[10,25,26]$. For instance, in rats with streptozotocin-induced diabetes, a significant increase in caspase- 3 expression has been reported in the nerve fiber layer, ganglion cell layer, and inner plexiform layer as early as after two weeks from diabetes induction [27]. An increase in the cytosol concentration of cytochrome c, secondary to the activation of caspase system, has also been observed in streptozotocin-exposed rats after 8 months from treatment [28]. In addition, a significant reduction of total retinal thickness and a decreased number of ganglion cells together with increased active caspase- 3 and TUNEL labeling were reported in rat and mouse models of type 2 diabetes [11, 29, 30]. Suffering of retinal neurons in diabetic rodent retinas is also suggested by altered expression of proteins involved in axonal transport in retinal neurons [31] and by the decrease in the content of synaptic proteins in retinal nerve terminals [32-34].

The neural cell types suffering alterations in early DR have been studied in more detail in different rodent models of DR. A number of investigations reported increased apoptosis of retinal ganglion cells [10, 26, 35-38]. Cholinergic [39], dopaminergic [37, 39, 40], and neuronal nitric oxide synthase-expressing [41] amacrine cells have been also observed to be affected in DR. Interestingly, a recent study reported significant reduction of dopamine levels in rodent models of DR, while visual function was improved by treatments with 1-DOPA or with dopaminergic receptor agonists [42]. In addition, alterations in retinal glutamatergic and GABAergic systems are suggested by the observed early transient changes in the content of glutamate and GABA vesicular transporters in retinal synaptosomes [43]. Other data documented photoreceptor death $[37,44,45]$ and alterations in the expression of phototransduction proteins [46], while a reduction in photoreceptor density close to the fovea has also been reported by a recent study in adult humans with diabetes [47]. However, the data relative to photoreceptor death or damage in diabetic retinas are not conclusive. Indeed, a number of investigations in animal models of DR reported lack of photoreceptor death and clinical studies failed to convincingly demonstrate photoreceptor damage in diabetic patients, as summarized in a recent review [48]. The presence of discrepancies about possible photoreceptor damage in DR may be explained, at least in some cases, assuming that observed photoreceptor loss or damage is due to factors other than diabetes (for instance, strain differences, in animal studies) or that the effects on photoreceptors are critically dependent on the duration of diabetes.

In addition to changes in the cell bodies (e.g., TUNELpositive nuclei and caspase-3 activation, indicating apoptosis), defects in the processes of retinal neurons are also evident in the retinas of rodent models of DR, and they are represented mainly by abnormal swellings observed in ganglion cell axons $[49,50]$ and morphologic changes in the dendrites of ON-type ganglion cells [50]. Observed signs of damage also include ganglion cell body swelling and axonal fragmentation [50] and closely mimic the pathologic features observed in postmortem human retinas from patients with diabetes [51]. Impairments at the level of ganglion cell axons are also documented by the finding of reduced efficiency of both retrograde and anterograde axonal transports and of reactive gliosis of axonal astrocytes in the optic nerve of diabetic rats $[52,53]$.

The damage to retinal neurons in early phases of DR is likely to be responsible for the functional deficits observed both in animal models of DR and in patients with diabetes. For instance, in diabetic $\mathrm{db} / \mathrm{db}$ mice, retinal thinning and ganglion cell apoptosis have been found to correlate with pattern ERG alterations [11]. This assumption is also supported by the observations reported in a recent retrospective case-control cohort study including eyes of diabetic patients with resolved diabetic macular edema (DME) and eyes of age-matched diabetic patients without maculopathy. Using measures of retinal thickness, obtained with SD-OCT, and measures of visual acuity, this study showed a significant correlation between thinning of the ganglion cell layer and visual acuity in patients with resolved DME, suggesting that retinal alterations occurring in DME and DR may lead to permanent visual deficiency [54]. Studies in animal models showed that, in rats with experimentally induced diabetes, 
ganglion cells exhibit the greatest level of dysfunction within the components of the electroretinogram (ERG) [55], while significant decreases in the rod and cone ERG components have been also reported $[45,56]$. ERG abnormalities have been reported in $\mathrm{db} / \mathrm{db}$ diabetic mice [29], while ERG deficits have been recorded in streptozotocin treated rats as early as 2 weeks after diabetes induction [57], indicating that functional abnormalities may be due to malfunctioning of neurons starting well before the appearance of clear signs of apoptotic cell death. In diabetic patients, earlier studies reported abnormalities in the ERG [58] and, more recently, a number of electrophysiological investigations in patients with diabetes, but with no or mild signs of vascular damage, have identified deficits of retinal functions in multiple layers of the retina [59-63]. In addition, color vision and contrast sensitivity are also affected in patients with diabetes [64, 65]. Electrophysiological and psychophysical observations have recently reported abnormalities of retinal function in diabetic patients without any evidence of microvascular changes [66]. In adolescents and young adults with type 1 diabetes but without or with mild nonproliferative DR, as well as in type 1 diabetic patients with normal ocular fundus and absent breakdown of the blood-retina barrier, multifocal ERG (mfERG) showed global retinal dysfunction $[67,68]$, confirming that changes in retinal function occur before the onset of vascular pathology.

Together, these data document the important role that neurodegenerative phenomena may play in the retina of a diabetic subject before the classical signs of DR are recognizable and support the view that a neuroprotective strategy should be considered for the treatment of patients before the appearance of vascular lesions.

2.2. Possible Causes of Neurodegeneration in DR. A logic consequence of the observation that neurons are damaged in DR is the search for the possible causes of this fact. A knowledge of the mechanisms that are likely to affect neuronal survival in the diabetic retina is an essential prerequisite to design therapeutic strategies aimed at reducing the impact of diabetes on retinal neurons.

2.2.1. Advanced Glycation End-Products (AGEs). AGEs are late products of nonenzymatic glycation. The deposition of hyperglycemia-induced AGEs in retinal blood vessels plays an important role in the onset and development of DR. AGEs and their receptors (RAGEs) have been detected in virtually all cellular types of the diabetic retina [69]. The AGE-RAGE axis plays a central role in the inflammation and microvascular dysfunction in DR [70], since AGEs have been found to stimulate apoptosis of retinal pericytes [71, 72] and of vascular endothelial cells [73, 74]. However, the potential effects of these compounds on the survival of retinal neurons are not fully elucidated. RAGE activation may induce retinal neuron apoptosis through activation of nitric oxide synthase [75] or may activate astrocytes and Müller glia promoting the expression of proinflammatory cytokines [76] that would contribute to neuronal death. A correlation between AGE and neuronal death is suggested by the observations that treatments reducing AGE formation also result in significant reduction of neuronal death in retinas of $\mathrm{db} / \mathrm{db}$ diabetic mice [77] and that in diabetic rats AGE blockade prevents both ERG abnormalities and ganglion cell apoptosis [78]. A direct evidence of detrimental effects of AGEs on retinal neurons is provided by results showing that AGEs induce neuronal death in nondiabetic retinal explants of both rat $[79,80]$ and mouse [81] retinas.

2.2.2. Glutamate Excitotoxicity. Glutamate is the major excitatory neurotransmitter in the retina and glutamate excitotoxicity is the process damaging or killing neurons expressing NMDA or AMPA receptors due to excessive receptor stimulation and calcium influx secondary to altered levels of glutamate in the extracellular space. Elevated glutamate levels have been observed in experimental models of diabetes [8284], where alterations of the expression of glutamate receptors and calcium binding proteins have also been reported [8588]. An increase in glutamate levels has been detected in the vitreous of patients with advanced DR $[89,90]$, while an immunohistochemical analysis in human retinas of donor eyes from subjects with diabetes described changes in the expression of glutamate receptor subunits [91]. Together, these data indicate that diabetes disrupts retinal glutamate homeostasis and that in DR excitotoxic phenomena may cause serious damage to retinal neurons. The reasons for extracellular accumulation of glutamate in DR may involve different mechanisms. For instance, Müller cells may become less efficient in performing glutamate uptake [92] or in converting glutamate to glutamine due to reduced levels of the enzyme glutamine synthetase $[82,83]$, while a decreased oxidation of glutamate to alpha-ketoglutarate has also been reported in diabetic retinas [84].

2.2.3. Intracellular Pathways. The polyol pathway is activated in the presence of elevated intracellular glucose levels and it is linked with the progression of DR [93]. The rate-limiting enzyme in this pathway is aldose reductase, which produces sorbitol from glucose causing reduction of NADPH levels and depletion of glutathione. This glutathione depletion and the consequent increased oxidative stress are major inductors of retinal damage. The polyol pathway also promotes other mechanisms of cellular damage, including AGE formation and activation of the protein kinase C (PKC) pathway, which may lead to inflammation and growth factor imbalances [94]. Thus the polyol pathway can be regarded as a mediator of glucose toxicity that is responsible for a wide spectrum of abnormalities, including neural, glial, and vascular damage, detectable during the development of DR [95]. In line with this view, diabetic mice deficient in aldose reductase were protected from diabetes-induced impairments in contrast sensitivity and spatial frequency threshold [96]. In addition, the cellular membranes are impermeable to sorbitol and the inability of sorbitol to efflux out of the cell leads to its intracellular accumulation, causing cellular damage mainly due to osmotic imbalance. Although the exact mechanism of sorbitol-induced cell death is still uncertain, this process is likely to promote the progression of DR [97].

Poly(ADP ribose) protein (PARP), a nuclear enzyme involved in the regulation of a variety of cellular events, is 
another potential inductor of retinal damage in DR. Indeed, PARP is activated in diabetic retinas causing DNA damage and oxidative stress [98-100], while its inhibition results in increased neurotrophic support and reduction of neuronal damage in early experimental DR [101].

Hyperglycemia and diabetes also increase the function of the hexosamine biosynthetic pathway, which results in many changes in both gene and protein levels, contributing to the pathogenesis of DR [102]. In particular, the increased glucose flux through the hexosamine pathway may cause apoptosis of retinal neurons in two ways, that is, via induction of apoptosis due to altered glycosylation of proteins or via impairment of the neuroprotective effect of insulin mediated by Akt [103].

Activation of PKC is known to be implicated in several pathologic changes occurring in DR, such as basement membrane thickening, extracellular matrix expansion, vascular permeability, apoptosis, angiogenesis, leukocyte adhesion, and cytokine activation [2]. Similar to activation of the hexosamine pathway, also PKC activation is likely to result in retinal cell damage due to inhibition of insulin-induced Akt activation [104].

2.2.4. Oxidative Stress. A considerable increase of oxidative stress is known to occur in the diabetic retina $[105,106]$ and it is the likely cause of neurodegeneration [107]. The metabolic pathways discussed above are associated with mitochondrial overproduction of reactive oxygen species (ROS); therefore, oxidative stress may be regarded as a sort of final common pathway for the glucose-induced abnormalities found in DR. Oxidative stress may also result from nitrative stress [108, 109], activation of polyol or hexosamine pathways, or uncoupling of endothelial nitric oxide synthase [110]. In addition, oxidative stress and AGE production appear to be interrelated mechanism, since AGEs can induce oxidative stress through direct or indirect stimulation of ROS generation, while AGE synthesis is accelerated by oxidative stress $[105,111]$. Similarly, relationships between oxidative stress and glutamate release have also been reported [84]. In summary, oxidative stress is likely to increase the flux of polyol pathway as well as AGE and RAGE expression, to induce PKC overactivation and endothelial cell apoptosis and to promote inflammation [105]. Enhanced ROS levels may also cause retinal neuronal damage by reducing the expression of brain derived neurotrophic factor (BDNF). Indeed, in retinas of mice with streptozotocin-induced diabetes, reductions of both BDNF and synaptophysin have been reported, but these reductions were attenuated by the antioxidant lutein [107].

2.2.5. The Retinal Renin-Angiotensin System (RAS). The most well-known function of RAS is regulation of blood pressure as well as of fluid and electrolyte content in the body. The classical RAS is a systemic hormonal system, but local RASs have been identified in a number of organs, including the eye and the retina [112]. In DR, RAS is upregulated, with increased levels of renin, angiotensin converting enzyme (ACE), and angiotensin receptors (ATR) [113]. Retinal RAS is likely to be implicated in the development of vascular lesions in DR. Indeed, inhibitors of ACE, ATR, or aldosterone synthase reduce retinal neovascularization and VEGF expression in rodent models of DR and some benefit of RAS blockade in DR has been reported in clinical trials [114]. In retinas of diabetic animals, ACE inhibition and/or AT1R blockade have been reported to attenuate functional deficits [115-117] and to reduce oxidative stress, neurodegeneration, and mitochondrial dysfunction [118], indicating that RAS activation in DR may also affect retinal neurons.

2.2.6. Neuroinflammation. A considerable body of evidence from animal models and patients shows that DR is a chronic low-grade inflammatory disorder with participation of inflammatory mediators [119]. Dysregulation of metabolic pathways resulting in excessive mitochondrial ROS production, increased oxidative stress, and RAS activation leads to upregulation of a variety of growth factors and inflammatory cytokines, chemokines, prostaglandins, and inflammatory cells such as macrophages and neutrophils in a complex chain of events. The resulting alterations decrease vascular wall integrity, increasing vascular permeability, lumen occlusion, and ischemia $[119,120]$. Neuroinflammation involves the activation of microglia and astroglia. In contrast to microglia activation in acute inflammation, which may have beneficial effects, in chronic neuroinflammation microglia activation, resulting in release of proinflammatory mediators and increased oxidative stress [121], contributes to the pathogenesis of neurodegenerative diseases [122]. While the retinal microglia is likely to play important roles in DR, there is also strong evidence that Müller cells are major sources of inflammatory mediators [123] and become activated in response to a variety of pathological changes in the retina [124]. In particular, an analysis of gene expression in Müller cells from retinas of diabetic rats revealed 78 altered genes, of which one-third were associated with inflammation [125]. Sustained neuroinflammation creates a toxic milieu that may lead to detrimental effects in neuronal cells [126, 127], although the mechanisms by which these cytokines may contribute to neural apoptosis in DR have not been fully clarified.

2.2.7. Endoplasmic Reticulum (ER) Stress. ER stress results from an impairment of the folding capacity of the ER causing accumulation of unfolded proteins in the ER lumen and activation of the unfolded protein response (UPR). ER stress contributes to increased oxidative stress as well as inflammation and apoptosis may occur upon failure of UPR to resolve the ER stress. This condition is likely to be involved in the pathogenesis of different neuronal diseases in brain and retina, including the early stages of DR [128]. Disruption of glutamate homeostasis with consequent glutamatergic overstimulation, which has been described in DR (see above), may activate ER stress and apoptosis in retinal ganglion cells of mouse retinas [129]. In addition, data obtained using streptozotocin-treated rats reported that the expression of ER stress marker proteins in the retina is significantly increased by diabetes and that reducing ER stress results in protection of diabetic retinas from neuronal cell death and vascular damage [130]. 
2.2.8. Dysregulation of Endogenous Neuroprotectants. Insulin provides trophic support for retinal neurons via phosphatidylinositide 3-kinase/Akt and P70S6 kinase pathways [131133]. This constitutive insulin prosurvival signaling in the retina is impaired by diabetes and may contribute to neuronal degeneration in DR [134]. Similarly, insulin-like growth factors (IGFs) are neurotrophic factors that may be involved in the pathogenesis of DR. Indeed IGF-1 mRNA has been found to be reduced in the eye in early stages of clinical and experimental diabetes [135], while IGF replacement therapy counteracts proapoptotic abnormalities preceding retinal cell degeneration in diabetic rats [136].

Pigment epithelium-derived factor (PEDF) has been described as a multifunctional protein with neuroprotective, antiangiogenic, antivasopermeability, anti-inflammatory, and antioxidative effects [137]. Its levels are decreased in aqueous or vitreous of patients with diabetes, suggesting that a decrease of retinal PEDF levels in humans may contribute to the development of DR [138]. Consistent with the hypothesis that a reduction of PEDF may contribute to retinal neuronal death in DR, in vitro studies in retinal Müller cells suggest that PEDF could increase glutamine synthetase expression and prevent downregulation of glutamate transporter in these cells, thereby limiting glutamate excitotoxicity in the diabetic retina $[139,140]$.

Alterations in retinal levels of neurotrophins (NTs) and their receptors (tropomyosin receptor kinases, Trks, and p75 neurotrophin receptor, $\mathrm{p} 75^{\mathrm{NTR}}$ ) may be present in DR. Indeed, in the retina of streptozotocin-treated rats, the upregulation of NT-3 and NT-4 and of their receptors TrkA and TrkB is associated with the progression of DR [141]. In addition, impaired maturation of the nerve growth factor (NGF) precursor proNGF, caused by the oxidative milieu of the diabetic retina, results in increased expression of proNGF, with a corresponding decrease in NGF. The dysregulation of proNGF maturation in the diabetic retina may contribute to diabetes-induced retinal ganglion cell death through the reduction in trophic support due to decreased NGF expression or through the direct activation of proapoptotic pathways in ganglion cells by proNGF interaction with the $\mathrm{p} 75^{\mathrm{NTR}}$ receptor $[38,142,143]$. Another pathway by which proNGF may cause ganglion cell death involves paracrine effects of proNGF/p75 $5^{\mathrm{NTR}}$-mediated secretion of tumor necrosis factor- $\alpha$ by Müller cells [144]. Reduction of retinal levels of BDNF has also been reported in animal models of diabetes $[40,101,107,145]$, probably caused, at least in part, by oxidative stress [107]. This reduction may affect retinal neuronal survival, since exogenous supply of BDNF has been found to reduce neurodegeneration in an animal model of DR [40].

Interphotoreceptor retinoid-binding protein (IRBP) is a photoreceptor-secreted glycolipoprotein that is essential for photoreceptor survival [146]. IRBP levels are reduced in the vitreous, while both IRBP mRNA and protein are significantly lower in the retinas of donors with diabetes than in those of nondiabetic donors $[147,148]$. In addition, IRBP levels have been found to be negatively correlated with the levels of neurodegeneration in the retinas of patients with diabetes [148].

The neuropeptide somatostatin (SST), together with its receptors, is expressed in the retina, where it is involved in a variety of functions [149]. A downregulation of SST retinal expression has been reported in DR and it has been found to be associated with retinal neurodegeneration [150]. A decreased expression of SST in the retina results in marked decrease of intravitreal SST in the eyes of patients with proliferative DR $[151,152]$ or with diabetic macular edema [153]. SST is likely to play a dual action in DR, inhibiting both neoangiogenesis and neuronal death [149]. In particular, a major cause of neuronal death in diabetic retinas is increased extracellular glutamate and excitotoxicity, and SST may limit the extent of neuronal damage through inhibition of glutamate release [154-157] and of glutamate transporter downregulation [157].

\subsection{VEGF: A Proangiogenic or a Neuroprotective Factor?} Observations of the brain after ischemia suggest that brain damage, in addition to the activation of death pathways, also stimulates protective mechanisms to counteract the expansion of the injury. Although the damaging effectors in the end prevail, the evidence suggests that concomitant self-protective mechanisms are elicited, implying that the central nervous system possesses intrinsic cytoprotective mechanisms that are likely to be mediated by chemical signals derived from the injured brain itself [158]. VEGF may be one of such signals released by the retina in the early phases of DR. Indeed, we have shown that retinal neurons in ex vivo ischemic retinas not only undergo cell death but also express and release VEGF, which, in turn, is likely to bind to its receptors expressed by endothelial cells [156, 159]. These observations indicate that VEGF expression and release are among the earliest responses of suffering retinal neurons and that, in this context, the significance of VEGF release is unlikely to be related to its proangiogenic effects. Rather, VEGF expression and release are probably related to a protective strategy of the retina, which tries to protect its cells from damage. Consistent with this view, glutamate excitotoxicity, one of the major causes of retinal neuronal death in DR, has been reported to upregulate VEGF production in diabetic retinas [160], while inhibition of NMDA receptors results in a decrease in vitreoretinal VEGF in diabetic rats [161]. In addition, we have recently observed that VEGF expression and release markedly increase in retinal explants within a few days of incubation in the presence of high glucose, oxidative stress, or AGE and that these increases are abolished or significantly reduced by the addition of neuroprotectants [81]. Together, these observations suggest that, in an early phase of DR, VEGF is likely to be expressed and released to rescue and protect retinal neurons. In this phase, VEGF would not act as a proangiogenic but as a prosurvival factor. Interestingly, it has been reported that the optic nerve and retinal ganglion cells in a rat model of experimental glaucoma are protected from degeneration by short-term hyperglycemia [162]. Increased VEGF levels may negatively affect vessel permeability and the blood-retina barrier. Then, if the stressing conditions remain for a long 


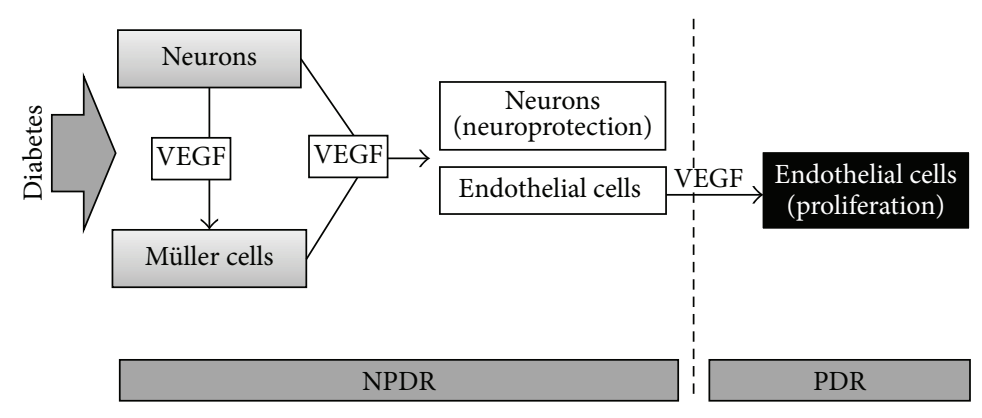

FIGURE 1: Possible role of VEGF in early DR. Under diabetic stress, VEGF would be immediately released by neurons and by Müller cells, which perhaps receive stimulation by the VEGF of neuronal origin. In the nonproliferative phase of DR (NPDR), released VEGF would act on retinal neurons as a neuroprotectant, while it would also bind to its receptors on endothelial cells. A prolonged interaction of VEGF with endothelial cells would lead to the proliferative phase of DR (PDR).

time, the persistent high levels of VEGF may lead to vessel proliferation (Figure 1). In the retina, VEGF neutralization has been reported to cause apoptosis of retinal cells and loss of retinal function [163], while VEGF blockade has been observed to significantly increase neuronal cell death in a hypertensive glaucoma model [164]. Repeated intravitreal injections of bevacizumab have been found to cause extensive neuronal loss in the rat retina [165]. Furthermore, VEGF has been found to be able to rescue retinal neurons after optic nerve axotomy [166] and to play a role in the survival of photoreceptors and of Müller cells [163]. Finally, using organotypic retinal explants cultured in hypoxic conditions, we have recently demonstrated that decreased VEGF release is accompanied by increased retinal cell apoptosis, while increased VEGF release results in reduced rate of retinal cell death [167]. Therefore, the possibility exists that the VEGF released by the retina in acute stress conditions, as we have demonstrated in ex vivo ischemic models of the retina [156, 159], may have the scope of protecting retinal neurons rather than that of promoting angiogenesis. One may wonder why, despite high levels of VEGF expression and release in diabetic retinas, neuronal death is still present, resulting in functional abnormalities. The possibility exists that the diabetic milieu may impair VEGF function uncoupling its survival effect, as suggested by investigations with retinal endothelial cells under high glucose or hypoxia $[168,169]$. In addition, a shift in VEGF splice variants reducing neuroprotective [170] and increasing proangiogenic VEGF isoforms [171], as well as the loss of other neuroprotective factors (i.e., somatostatin and IRBP) induced by diabetes, is other mechanisms promoting neuronal death even when an enhancement of VEGF does exist. VEGF neuroprotective actions in the retina are likely to be mediated by VEGF receptor 2 signaling via the phosphoinositide-3-kinase/Akt pathway, as demonstrated in different experimental models [164].

\section{Therapeutic Perspectives for Neuroprotection in DR}

3.1. Methods for Detecting Retinal Neurodegeneration in the Clinical Setting: A New Cornerstone for Clinical Trials? Improvements in diabetes care and management have been crucial in lowering the incidence and severity of DR. One limiting factor that has hampered the investigation of new drugs for DR is the low sensitive endpoints in the clinical trials, which require large sample sizes as well as a long duration (about 5 years) to achieve a sufficient statistical power to detect potential treatment effectiveness. Best corrected visual acuity (BCVA) and derived variables are the only endpoints that have served as the basis for regulatory approval of retinal drugs. However, BCVA captures only a small portion of visual function and patients with good BCVA may have difficulties with daily activities such as reading or driving. Therefore, there is now widespread recognition of the need for improved endpoints for DR research.

Since neurodegeneration is an early event in the pathogenesis of DR that could participate in the development of microvascular impairment $[14,66]$, the study of the underlying mechanisms leading to neurodegeneration and the identification of mediators in the cross-talk between neurodegeneration and microangiopathy are essential for the development of new therapeutic strategies. Currently, the presence of neurodegeneration can be measured by SD-OCT, which allows the examination of morphological changes (i.e., the thinning of the ganglion cell layer or of the nerve fiber layer), or by means of functional methods such as mfERG, standard automated perimetry, frequency doubling perimetry, or microperimetry.

Among the methods for assessing the functional impairment, the mfERG is the gold standard. This is a noninvasive technique providing a topographic measure of retinal electrophysiological activity. The use of mfERG has provided compelling evidence suggesting a direct link between neural dysfunction and vascular abnormalities in DR. Thus, a delayed mfERG implicit time predicts the development of early microvascular abnormalities [59, 172]. In addition, it should be noted that the implicit time is spatially associated with microvascular abnormalities, correlates with retinopathy severity, and is a predictor for the development of visible vascular impairment over 1-year $[173,174]$ or 3year period [172]. However, mfERG is a time-consuming and cumbersome examination and, consequently, its use is currently limited to pilot studies and clinical trials. 


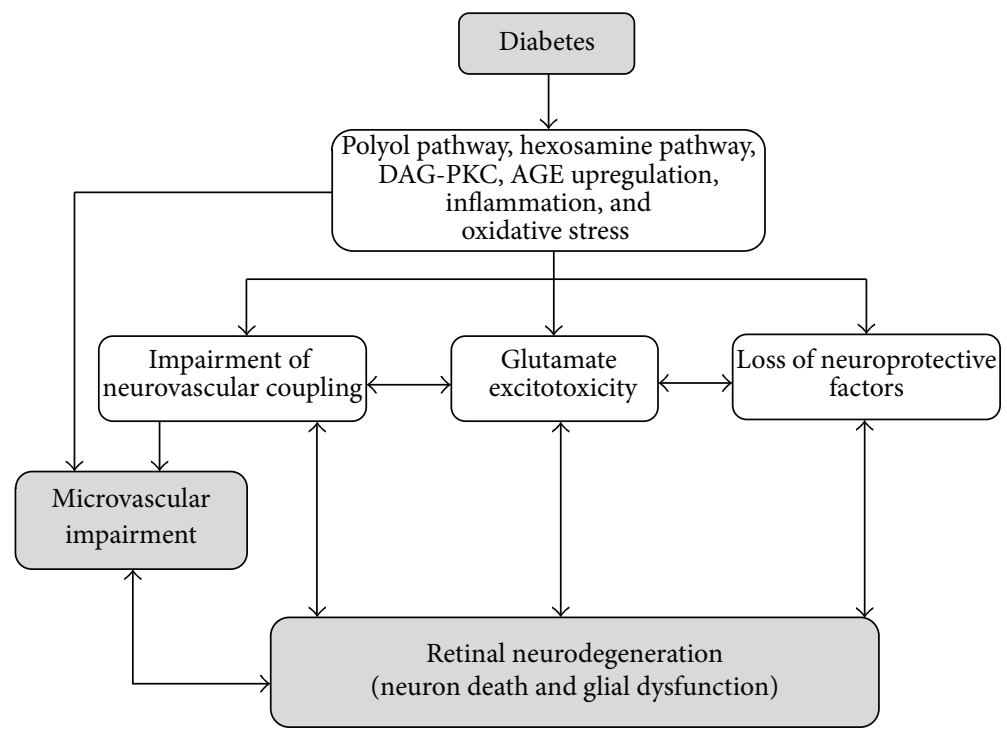

FIGURE 2: Potential therapeutic targets based on pathogenic mechanisms involved in retinal neurodegeneration induced by diabetes.

The current method for exploring the morphological changes in retina is the SD-OCT, which provides an anatomical image of the retina and complements the functional information obtained with mfERG. The reduction in the thickness of the ganglion cell layer and of the nerve fiber layer are the main parameters detected in DR and they have been observed even before any microvascular abnormality appears in the fundoscopic examination [66]. Hyperreflective intraretinal spots (HRS) can also be found in diabetic eyes without microangiopathy. HRS are mainly located in the inner retina, where the resident microglia are present and may represent a surrogate of microglial activation in the early stages of DR [175]. At present, SD-OCT seems to be the most practical method for monitoring neurodegeneration in DR.

In recent years a noninvasive instrument to assess mitochondrial function using flavoprotein autofluorescence has been developed. This method is based on the fact that the retina is particularly susceptible to oxidative stress because of high energy demands and light exposure. Before apoptosis, mitochondria exhibit impaired electron transport by energy generating enzymes in the respiratory chain, causing increased percentages of flavoproteins in the chain to be oxidized and rendered capable of absorbing blue light and emitting green autofluorescence [176]. Since oxidative stress and mitochondrial dysfunction are implicated in the pathogenesis of $\mathrm{DR}$, it is reasonable to expect that flavoprotein autofluorescence may be used for monitoring retinal damage [177]. However, clinical studies to validate this method are needed.

3.2. New Therapeutic Strategies Based on Administration of Neurotrophic Factors. There are several therapeutic strategies based on the main pathogenic mechanisms involved in retinal neurodegeneration that, theoretically, could be implemented (Figure 2). However, systemically administered drugs blocking these pathways can hardly reach the retina at pharmacological concentrations and, in addition, could have serious adverse effects. On the other hand, when the early stages of DR are the therapeutic target, it would be inconceivable to recommend an aggressive treatment such as intravitreal injections. For all these reasons, topical treatment could be envisaged as a revolutionary treatment.

The use of eye drops has not been considered an appropriate route for the administration of drugs aimed at preventing or arresting DR because of the general assumption that in this way the drugs do not reach the posterior chamber of the eye (i.e., the vitreous and the retina). However, there is emerging evidence showing that several topically administered compounds are able to reach the retina in pharmacological concentrations, at least in animal models [178-181]. In addition, topical administration of drugs limits their action to the eye and minimizes associated systemic effects [182].

Adherence to ophthalmic treatments has a unique set of challenges compared to oral medications [183]. It must be noted that self-administering drops (i.e., for glaucoma treatment) requires coordination, manual dexterity, eyehand coordination, and good vision. In addition, diabetic patients are commonly receiving a lot of treatments due to the high prevalence of comorbidities. However, it must be noted that a significant barrier to adherence is lack of information (failing to explain the benefit of a medication adequately). In this regard, it has been demonstrated that patients are more likely to be adherent to their medication if they understand the disease and the rationale for treatment. Therefore, educating the patient and his/her family could improve patient adherence to topical ocular therapy.

Pathologic conditions, including those characterizing the diabetic status, are known to affect retinal levels of neuroprotective agents, thus impairing the balance between neurotoxic and neuroprotective factors and resulting in damage to the neural retina. In this respect, many different substances have 
been tested for their neuroprotective properties in models of retinal stress similar to that in DR. Since a comprehensive review of all the substances employed in experimental studies is virtually impossible, we will briefly consider the potential use in DR of endogenous neuroprotective substances or of phytochemicals with antioxidant and anti-inflammatory properties.

3.2.1. Endogenous Neuroprotective Substances. Insulin, IGF1, PEDF, SST, pituitary adenylate cyclase activating peptide (PACAP), glucagon-like peptide- (GLP-) 1, and NTs are potential neuroprotective factors for the treatment of DR.

Subconjunctival insulin administration restores prosurvival signaling and reduces the rate of retinal cell death in streptozotocin-induced diabetic rats [184]. In this regard, it has been reported that insulin hydrogels can be implanted subconjunctivally for long term insulin delivery to the eye without any adverse events in rats [185]. IGFs are neurotrophic factors implicated in the pathogenesis of diabetic neurological disorders and treatment with IGF-1 analogs prevents early retinal biochemical abnormalities implicated in the progression of DR [136].

PEDF is a peptide with neurotrophic properties produced by retinal pigment epithelium cells and found to have neuroprotective effects towards photoreceptors [186]. In addition, systemic administration of PEDF to diabetic rats prevents Müller cell activation and retinal dysfunction [187]. On the other hand, PEDF is also a potent antiangiogenic factor [188] and intravitreal PEDF effectively reduces VEGF-induced vascular permeability in a mouse model of nonproliferative DR [189]. In addition, PEDF also exerts antioxidant and antiinflammatory effects and reduces oxidative stress and the production of inflammatory markers in DR models [190]. Moreover, in vitro studies in retinal Müller cells suggest that PEDF decreases glutamate excitotoxicity induced by the diabetic milieu by increasing the expression of glutamine synthetase and by preventing glutamate transporter downregulation $[139,140]$. Finally, intravitreal administration of PEDF upregulates glutamine synthetase and glutamate transporter expression and decreases glutamate levels in hypoxia [191]. Taken together, these findings suggest that multitarget molecules such as PEDF may be suitable candidates for new therapeutic approaches to treat DR. However, PEDF size may limit its utility as a topical therapeutic agent and, therefore, some synthetic PEDF-derived peptides containing biologically active fragments are needed. In this regard, the amino acid residues of PEDF contributing to the inhibition of VEGF-induced vascular permeability [189] and a PEDF fragment inhibiting retinal vascularization in an oxygen-induced retinopathy model [192] have been identified. Regarding $\mathrm{DR}$, the topical administration (eye drops) of antiangiogenic PEDF60-77 and neuroprotective PEDF78-121 derivatives reduced neurodegeneration and microvascular leakage in the Ins2(Akita) mouse [193]. Furthermore, eye drop delivery of PEDF-34 promotes ganglion cell survival and axon regeneration after optic nerve crush injury in rats [194].

The neuropeptide SST and its five receptor subtypes ( sst $_{1}-$ sst $_{5}$ ) are expressed in the retina, where they are involved in multiple functions [195]. SST acting at sst $_{2}$ expressed by bipolar cells may control glutamate release in the retina $[154,155,196]$, suggesting that SST may protect neurons from apoptosis caused by extracellular glutamate levels in DR. In this respect, the first evidence has been provided that topical administration of SST prevents retinal neurodegeneration in streptozotocin-induced diabetic rats [157]. The main mechanism involved in this beneficial effect is indeed the reduction of glutamate-induced excitotoxicity. With this basis, a multicentric, phases II-III, randomized controlled clinical trial (EUROCONDOR) to assess the efficacy of SST administered topically (eye drops) to prevent or arrest retinal neurodegeneration is ongoing (EudraCT number: 2012-001200-38). This study has been funded by the European Commission in the setting of the FP7-HEALTH-2011 and the results will be available in April 2016.

PACAP is known to be protective against a variety of insults in mammalian retinas [197]. In particular, neuroprotective effects of PACAP against retinal cell loss induced by ischemia have been reported both in vivo and in vitro [156, 198]. In addition, neurodegeneration of several retinal cell types, including dopaminergic amacrine cells and ganglion cells, is counteracted by PACAP in streptozotocin-treated rats [37].

GLP-1 exerts neuroprotective effects in both central and peripheral nervous systems [199]. It has been shown that intravitreal injections of exendin-4 (a GLP-1R agonist) prevent ERG abnormalities and morphological features related to neurodegeneration in rats with streptozotocin-induced diabetes [200] and in Goto-Kakizaki rats [201]. Recently, abundant expression of GLP-1 receptor (GLP-1R) in human retinas has been observed [202]. In addition, both neuroprotection and prevention of vascular leakage have been reported using topical administration (eye drops) of GLP-1R agonists in the $\mathrm{db} / \mathrm{db}$ mouse model [202].

Originally identified as trophic factors for neurons, NTs are a family of structurally and functionally related proteins that are essential for the growth, differentiation, and survival of several cell types including retinal neurons, glia, and endothelial cells [144]. The main members of this family are BDNF and NGF. In diabetic rats, retinal levels of BDNF are decreased, and intravitreal administration of exogenous BDNF rescues amacrine cells from neurodegeneration [40]. In addition, overexpression of BDNF in streptozotocininduced diabetic rats, obtained by intraocular injection of an adenoassociated virus vector plasmid carrying the expression cassette of brain BDNF, resulted in enhanced ganglion cell survival and function [203]. The neuroprotective effect of BDNF in the retina seems to be mediated, at least in part, by prevention of the cytotoxic swelling of retinal glial and bipolar cells [204]. NGF plays an important role in neurodegeneration, inflammation, vascular permeability, and injury, all important processes in the pathogenesis of DR. There is no report on retinal production of NGF. However, its administration in rat models of diabetes is effective in counteracting retinal neurodegeneration. Indeed, intraocular injections of NGF prevent apoptosis in retinal ganglion cells and in Müller cells as well as pericyte loss and the formation of acellular capillaries [205]. Recently, applications of NGF as eye drops have been reported to protect retinal ganglion 
cells from degeneration in models of experimental glaucoma or DR [206].

\subsubsection{Antioxidant and Anti-Inflammatory Agents. Many} papers suggest that oxidative stress plays a major role in the pathogenesis of DR. Therefore, the use of antioxidants may be viewed as potential therapeutics in the treatment of DR. Many phytochemicals have been extensively examined, although much more work is needed to definitely assess their effectiveness as alternative therapies in DR.

Flavonoids possess antioxidant, antiangiogenic, and antiinflammatory properties; thus selected flavonoids may be effective in the prevention or treatment of ocular diseases, including DR [207]. In this respect, quercetin reduces oxidative stress, neuroinflammation, and apoptosis in streptozotocin-treated rats. Indeed, six-month treatment with quercetin restores glutathione levels and the activities of antioxidant enzymes, reduces the levels of inflammatory cytokines, and protects ganglion cells from apoptotic cell death [208]. Numerous studies have investigated the role of resveratrol in preventing or treating diabetic complications, including DR. Four-month oral administration of resveratrol to streptozotocin-treated rats partially prevents the decrease in antioxidant defenses, retinal thinning, production of inflammatory cytokines, and retinal cell apoptosis, without affecting plasma levels of insulin [209, 210]. Resveratrol also reduces retinal expression of genes involved in angiogenesis, inflammation, and oxidative stress in diabetic rats [211]. The antioxidant and antiangiogenic actions of curcumin have been regarded as suitable characteristics in order to propose curcumin as a novel drug for the treatment of DR. Twomonth administration of curcumin to streptozotocin-treated rats inhibits the expression of VEGF [212], while three-month treatment with curcumin inhibits oxidative stress protects Müller cells and prevents the downregulation of glutamine synthase in the retina of diabetic rats [213]. A four-month treatment with curcumin induces significant hypoglycemic activity, reduces the decrease in glutathione levels and in the activity of antioxidant enzymes, decreases inflammatory factor levels, and prevents the structural degeneration and increase in capillary basement membrane thickness in the retina of diabetic rats [214]. Treatment with the flavonoid hesperetin for six months rescues the retina from oxidative stress, neuroinflammation, and apoptosis in diabetic rats [215]. Genistein, administered to streptozotocin-treated rats, attenuates retinal inflammation by targeting microglial activation [216] and confers protection against gliopathy and vasculopathy [217]. Interestingly, oral administration of genistein in association with $\alpha$-lipoic acid and vitamins to preretinopathic diabetic patients, increases plasma levels of antioxidants, and ameliorates electroretinographic recordings [218]. Finally, epigallocatechin gallate protects the retina against glutamate toxicity through an antioxidant mechanism in diabetic spontaneously hypertensive rats [219].

Carotenoids are also powerful antioxidants. In particular, lutein and zeaxanthin, which in diabetes are decreased in serum and retina, have been reported to inhibit diabetesinduced retinal oxidative damage [220, 221]. Treatment with zeaxanthin has been tested in a large trial on age-related macular degeneration with moderate success [222].

Overall, data from literature indicate phytochemicals (not only flavonoids or carotenoids, as briefly described here, but also phenolic acids, terpenoids, etc.) as effective molecules in the management of retinal complications in diabetes, although further investigations using human clinical studies are needed to confirm the beneficial effects of phytochemicals in the treatment of DR.

Given that diabetic murine models do not develop advanced vascular abnormalities, the experimental studies mentioned above have demonstrated the usefulness of neuroprotective agents to prevent the development of retinal neurodegeneration and initial vascular leakage. Although it could be reasonable to speculate that neuroprotection of the retina will be useful at any stage of DR, further evidence demonstrating this issue is needed. In particular, more work both in animal models, using sufficiently large numbers of animals to have statistical power, and in the clinics is necessary to provide conclusive demonstration that neuroprotection not only preserves neurons from death or damage but also results in actual functional improvements.

\subsection{Other Approaches}

3.3.1. Improving the Neurovascular Coupling Function. Alterations of the neurosensory retina and retinal vasculature are integrally linked, and the study of the interactions between blood vessels and the neurosensory retina is crucial to understand the pathogenesis of DR. Neurovascular coupling is the intrinsic physiological mechanism by which neural activity is coupled to blood flow and metabolism, thus enabling the retina to regulate blood flow in response to neural activity or metabolic demands. Indeed, the increased delivery of oxygen in response to the increased activity of retinal neurons is a consequence of the coupling between neural activity and the vasculature. The neurovascular coupling in the retina is altered in diabetes [223].

Visual stimulation is a powerful modulator of retinal and optic nerve blood flow [224]. Since the blood vessels do not directly respond to light, light-induced changes in blood flow or oxygen delivery must be initiated by light-induced changes in neural activity of the retina. An increase of neural activity leads to retinal arterial and venous dilation [225]. Flicker light stimulation (intermittent flash) has been used to investigate this process, which results altered in diabetic patients without structural microvascular abnormalities in the retina [226228].

The retina has a high metabolism and $\mathrm{O}_{2}$ consumption and, therefore, is particularly susceptible to hypoxia caused by compromised blood flow. The loss of this vascular response could starve the retina of needed oxygen and glucose, putting neurons at risk and contributing to retinal pathology. The improvement of functional hyperaemia could be a useful therapeutic target. In this regard, it has been demonstrated that blocking inducible nitric oxide synthase with systemic administration of aminoguanidine recovers flicker-evoked vasodilation in diabetic retinas [229]. 
Among the mediators of the hemodynamic impairment of the neurovascular coupling that occurs in diabetic patients, endothelin seems to play a significant role. It should be noted that endothelin 1 (ET-1), a potent vasoconstrictor, is overexpressed in endothelial cells in the setting of DR and enhances glutamate-induced neurotoxicity in retinal neural cells $[230,231]$. In addition, it is worth mentioning that, through ETB receptors, ET-1 contributes to retinal ganglion cell loss in rat models of glaucoma and optic nerve injury [231, 232]. Moreover, progressive retinal neurodegeneration has been found in transgenic mice with an overexpression of ET-1 in vascular endothelial cells [233]. Finally, it has been recently demonstrated that the blockade of ETA receptors, apart from ameliorating retinal vascular pathology by reducing pericyte loss and acellular capillaries, prevents thinning in both the optic nerve and retinal periphery in $\mathrm{db} / \mathrm{db}$ mice [234]. Therefore, ET-1 seems to be a key player involved in the cross-talk between neurodegeneration and vascular abnormalities in the setting of DR. For this reason, the inhibition of ET-1 could lead not only to an improvement in microvascular hemodynamics in the retina, but also to an amelioration of the retinal neurodegeneration associated with diabetes. However, clinical trials are needed to confirm these experimental findings.

3.3.2. Blocking Glutamate Signaling Pathway. Since the extracellular accumulation of glutamate plays a key role in retinal neuron death, treatments addressed at reducing glutamate levels seem appropriate. In this regard, substances targeting the glutamate receptors, such as memantine, have shown beneficial effects on neurodegeneration and vascular abnormalities in streptozotocin-induced diabetic rats [235]. Memantine has failed in demonstrating neuroprotection in phase III clinical trials for glaucoma [236]. However, since the pathophysiology of retinal neurodegeneration is different in diabetes and glaucoma, specific studies examining whether or not memantine may exert a neuroprotective effect in the diabetic retina are needed.

3.3.3. Cell-Based Therapies. Several potential therapies using endothelial precursor cells have been explored. However, the usefulness and safety of these approaches for DR remain to be determined. Regarding retinal development and transplantation strategies, the last decade has seen an enormous progress in the research for photoreceptor replacement and regeneration [237]. Restoration of visual function by cell replacement seems to be a real possibility for neurodegenerative diseases such as retinitis pigmentosa.

\section{New Perspectives}

The advances in both retinal imaging and functional assessment will allow detecting early changes and will accelerate drug discovery and delivery strategies to improve visual prognosis in diabetic patients. In addition, this new approach will encourage the implementation of personalized treatments. In this regard, OCT angiography and confocal adaptive optics scanning ophthalmoscope (AOSLO) are two new technologies that will play a key role in the near future for the diagnosis and monitoring of treatments in early stages of DR. OCT angiography proved to be capable of showing 10 micron-thick blood vessels, revealing the areas of vascular nonperfusion and identifying microexudates that were not otherwise visible on clinical examination and fundus photography. Moreover, OCT angiography allows appreciation of spatial relationships of fundus vessels and makes it possible to separately visualize the large retinal vessels as well as the superficial and the deep capillary plexus [238]. Adaptive optics imaging can be expected to add new aspects to the knowledge of DR because photographic resolution has improved by reducing the influence of optical aberrations on retinal imaging [239]. The confocal AOSLO allows seeing details of the microvasculature, photoreceptors, and hemorheologic parameters and, therefore, is a promising noninvasive and direct method for examining physiopathological events that are taking place in the retina of diabetic patients and may be used for evaluating the effects of clinical interventions [239, 240]. In this regard, clinical trials aimed at examining the effect of controlling the risk factors and new treatments on the diameter of retinal vessels and blood flow would be of particular interest.

From the therapeutic point of view, as previously mentioned, when the early stages of DR are the therapeutic target it would be inconceivable to recommend an aggressive treatment such as intravitreal injections. There is experimental evidence that topical administration is effective for the treatment of early stages of DR [157, 194, 202]. Therefore, the topical route of drug delivery for the treatment of DR could be envisaged as a revolutionary treatment, particularly at the early stages of the disease. However, less than $5 \%$ of topically applied dose reaches the deeper ocular tissues [241]. To overcome the ocular drug delivery barriers and improve retinal bioavailability, conventional and novel drug delivery systems are being developed.

In conclusion, the central role of neurodegeneration in the pathogenesis of DR is a solid basis for proposing neuroprotection as an effective strategy for preventing or arresting DR. However, clinical trials to determine not only the effectiveness and safety, but also the compliance of a noninvasive route of drug delivery, as well as a standardization of the methods for monitoring neurodegeneration, are needed. In addition, neuroprotection in the setting of DR should be contemplated as an early treatment; therefore, this exciting experimental approach seems to be still far from acceptance in clinical practice.

\section{Competing Interests}

The authors declare that there is no conflict of interests regarding the publication of this paper.

\section{Acknowledgments}

This study was supported by grants from the Italian Ministero dell'Istruzione, dell'Università e della Ricerca, from the Università di Pisa (PRA-2016), from the Spanish Ministerio de Economía y Competitividad (PI13/00603), and from the Catalan Agència de Gestió d'Ajuts Universitaris i de Recerca (2014 SGR 270). 


\section{References}

[1] S. F. Abcouwer and T. W. Gardner, "Diabetic retinopathy: loss of neuroretinal adaptation to the diabetic metabolic environment," Annals of the New York Academy of Sciences, vol. 1311, pp. 174190, 2014.

[2] M. S. Ola, M. I. Nawaz, M. M. Siddiquei, S. Al-Amro, and A. M. Abu El-Asrar, "Recent advances in understanding the biochemical and molecular mechanism of diabetic retinopathy," Journal of Diabetes and Its Complications, vol. 26, no. 1, pp. 5664, 2012.

[3] H. Qian and H. Ripps, "Neurovascular interaction and the pathophysiology of diabetic retinopathy," Experimental Diabetes Research, vol. 2011, Article ID 693426, 11 pages, 2011.

[4] J. M. Tarr, K. Kaul, M. Chopra, E. M. Kohner, and R. Chibber, "Pathophysiology of diabetic retinopathy," ISRN Ophthalmology, vol. 2013, Article ID 343560, 13 pages, 2013.

[5] D. A. Antonetti, A. J. Barber, S. K. Bronson et al., "Diabetic retinopathy: seeing beyond glucose-induced microvascular disease," Diabetes, vol. 55, no. 9, pp. 2401-2411, 2006.

[6] C. Hernández and R. Simó, "Neuroprotection in diabetic retinopathy," Current Diabetes Reports, vol. 12, no. 4, pp. 329337, 2012.

[7] V. Jindal, "Neurodegeneration as a primary change and role of neuroprotection in diabetic retinopathy," Molecular Neurobiology, vol. 51, no. 3, pp. 878-884, 2015.

[8] X. Zhang, N. Wang, G. R. Barile, S. Bao, and M. Gillies, "Diabetic retinopathy: neuron protection as a therapeutic target," International Journal of Biochemistry and Cell Biology, vol. 45, no. 7, pp. 1525-1529, 2013.

[9] R. Simó and C. Hernández, "Novel approaches for treating diabetic retinopathy based on recent pathogenic evidence," Progress in Retinal and Eye Research, vol. 48, pp. 160-180, 2015.

[10] A. J. Barber, E. Lieth, S. A. Khin, D. A. Antonetti, A. G. Buchanan, and T. W. Gardner, "Neural apoptosis in the retina during experimental and human diabetes. Early onset and effect of insulin," The Journal of Clinical Investigation, vol. 102, no. 4, pp. 783-791, 1998.

[11] Q. Yang, Y. Xu, P. Xie et al., "Retinal neurodegeneration in $\mathrm{db} / \mathrm{db}$ mice at the early period of diabetes," Journal of Ophthalmology, vol. 2015, Article ID 757412, 9 pages, 2015.

[12] M. Villarroel, A. Ciudin, C. Hernandez, and R. Simo, "Neurodegeneration: an early event of diabetic retinopathy," World Journal of Diabetes, vol. 1, no. 2, pp. 57-64, 2010.

[13] A. J. Adams and M. A. Bearse Jr., "Retinal neuropathy precedes vasculopathy in diabetes: a function-based opportunity for early treatment intervention?" Clinical and Experimental Optometry, vol. 95, no. 3, pp. 256-265, 2012.

[14] A. J. Barber, "A new view of diabetic retinopathy: a neurodegenerative disease of the eye," Progress in Neuro-Psychopharmacology and Biological Psychiatry, vol. 27, no. 2, pp. 283-290, 2003.

[15] R. A. Feit-Leichman, R. Kinouchi, M. Takeda et al., "Vascular damage in a mouse model of diabetic retinopathy: relation to neuronal and glial changes," Investigative Ophthalmology and Visual Science, vol. 46, no. 11, pp. 4281-4287, 2005.

[16] J. Yu, L. Wang, S.-J. Weng, X.-L. Yang, D.-Q. Zhang, and Y.M. Zhong, "Hyperactivity of ON-type retinal ganglion cells in streptozotocin-induced diabetic mice," PLoS ONE, vol. 8, no. 9, Article ID e76049, 2013.

[17] R. A. Gubitosi-Klug, R. Talahalli, Y. Du, J. L. Nadler, and T. S. Kern, "5-Lipoxygenase, but not 12/15-lipoxygenase, contributes to degeneration of retinal capillaries in a mouse model of diabetic retinopathy," Diabetes, vol. 57, no. 5, pp. 1387-1393, 2008.

[18] A. M. Abu-El-Asrar, L. Dralands, L. Missotten, I. A. Al-Jadaan, and K. Geboes, "Expression of apoptosis markers in the retinas of human subjects with diabetes," Investigative Ophthalmology and Visual Science, vol. 45, no. 8, pp. 2760-2766, 2004.

[19] T. Oshitari, S. Yamamoto, N. Hata, and S. Roy, "Mitochondriaand caspase-dependent cell death pathway involved in neuronal degeneration in diabetic retinopathy," British Journal of Ophthalmology, vol. 92, no. 4, pp. 552-556, 2008.

[20] A. M. Abu El-Asrar, L. Dralands, L. Missotten, and K. Geboes, "Expression of antiapoptotic and proapoptotic molecules in diabetic retinas," Eye, vol. 21, no. 2, pp. 238-245, 2007.

[21] H. W. van Dijk, P. H. B. Kok, M. Garvin et al., "Selective loss of inner retinal layer thickness in type 1 diabetic patients with minimal diabetic retinopathy," Investigative Ophthalmology and Visual Science, vol. 50, no. 7, pp. 3404-3409, 2009.

[22] H. W. van Dijk, F. D. Verbraak, P. H. B. Kok et al., "Decreased retinal ganglion cell layer thickness in patients with type 1 diabetes," Investigative Ophthalmology and Visual Science, vol. 51, no. 7, pp. 3660-3665, 2010.

[23] H. W. van Dijk, F. D. Verbraak, P. H. Kok et al., "Early neurodegeneration in the retina of type 2 diabetic patients," Investigative Opthalmology \& Visual Science, vol. 53, no. 6, pp. 2715-2719, 2012.

[24] J. Chhablani, A. Sharma, A. Goud et al., "Neurodegeneration in type 2 diabetes: evidence from spectral-domain optical coherence tomography," Investigative Ophthalmology and Visual Science, vol. 56, no. 11, pp. 6333-6338, 2015.

[25] A. J. Barber, D. A. Antonetti, T. S. Kern et al., "The Ins2Akita mouse as a model of early retinal complications in diabetes," Investigative Ophthalmology and Visual Science, vol. 46, no. 6, pp. 2210-2218, 2005.

[26] P. M. Martin, P. Roon, T. K. Van Ells, V. Ganapathy, and S. B. Smith, "Death of retinal neurons in streptozotocin-induced diabetic mice," Investigative Ophthalmology and Visual Science, vol. 45, no. 9, pp. 3330-3336, 2004.

[27] Y.-H. Li, Y.-H. Zhuo, L. Lü et al., "Caspase-dependent retinal ganglion cell apoptosis in the rat model of acute diabetes," Chinese Medical Journal, vol. 121, no. 24, pp. 2566-2571, 2008.

[28] R. A. Kowluru and S. N. Abbas, "Diabetes-induced mitochondrial dysfunction in the retina," Investigative Ophthalmology and Visual Science, vol. 44, no. 12, pp. 5327-5334, 2003.

[29] P. Bogdanov, L. Corraliza, J. A. Villena et al., “The db/db mouse: a useful model for the study of diabetic retinal neurodegeneration," PLoS ONE, vol. 9, no. 5, Article ID e97302, 2014.

[30] J. H. Yang, H. W. Kwak, T. G. Kim, J. Han, S. W. Moon, and S. Y. Yu, "Retinal neurodegeneration in type II diabetic Otsuka long-evans Tokushima fatty rats," Investigative Ophthalmology and Visual Science, vol. 54, no. 6, pp. 3844-3851, 2013.

[31] F. I. Baptista, M. J. Pinto, F. Elvas, T. Martins, R. D. Almeida, and A. F. Ambrósio, "Diabetes induces changes in KIF1A, KIF5B and dynein distribution in the rat retina: implications for axonal transport," Experimental Eye Research, vol. 127, pp. 91-103, 2014.

[32] T. S. D'Cruz, B. N. Weibley, S. R. Kimball, and A. J. Barber, "Posttranslational processing of synaptophysin in the rat retina is disrupted by diabetes," PLoS ONE, vol. 7, no. 9, Article ID e44711, 2012.

[33] J. M. Gaspar, F. I. Baptista, J. Galvão, Á. F. Castilho, R. A. Cunha, and A. F. Ambrósio, "Diabetes differentially affects the 
content of exocytotic proteins in hippocampal and retinal nerve terminals," Neuroscience, vol. 169, no. 4, pp. 1589-1600, 2010.

[34] H. D. VanGuilder, R. M. Brucklacher, K. Patel, R. W. Ellis, W. M. Freeman, and A. J. Barber, "Diabetes downregulates presynaptic proteins and reduces basal synapsin I phosphorylation in rat retina," European Journal of Neuroscience, vol. 28, no. 1, pp. 111, 2008.

[35] T. S. Kern and A. J. Barber, "Retinal ganglion cells in diabetes," Journal of Physiology, vol. 586, no. 18, pp. 4401-4408, 2008.

[36] X. Liu, Z. Zuo, W. Liu et al., "Upregulation of Nogo receptor expression induces apoptosis of retinal ganglion cells in diabetic rats," Neural Regeneration Research, vol. 9, no. 8, pp. 815-820, 2014.

[37] K. Szabadfi, T. Atlasz, P. Kiss et al., "Protective effects of the neuropeptide PACAP in diabetic retinopathy," Cell and Tissue Research, vol. 348, no. 1, pp. 37-46, 2012.

[38] T. K. Ali, S. Matragoon, B. A. Pillai, G. I. Liou, and A. B. ElRemessy, "Peroxynitrite mediates retinal neurodegeneration by inhibiting nerve growth factor survival signaling in experimental and human diabetes," Diabetes, vol. 57, no. 4, pp. 889-898, 2008.

[39] M. J. Gastinger, R. S. J. Singh, and A. J. Barber, "Loss of cholinergic and dopaminergic amacrine cells in streptozotocindiabetic rat and Ins $2^{\text {Akita }}$-diabetic mouse retinas," Investigative Ophthalmology \& Visual Science, vol. 47, no. 7, pp. 3143-3150, 2006.

[40] M. Seki, T. Tanaka, H. Nawa et al., "Involvement of brainderived neurotrophic factor in early retinal neuropathy of streptozotocin-induced diabetes in rats: therapeutic potential of brain-derived neurotrophic factor for dopaminergic amacrine cells," Diabetes, vol. 53, no. 9, pp. 2412-2419, 2004.

[41] E. Roufail, T. Soulis, E. Boel, M. E. Cooper, and S. Rees, "Depletion of nitric oxide synthase-containing neurons in the diabetic retina: reversal by aminoguanidine," Diabetologia, vol. 41, no. 12, pp. 1419-1425, 1998.

[42] M. H. Aung, H. N. Park, M. K. Han et al., "Dopamine deficiency contributes to early visual dysfunction in a rodent model of type 1 diabetes," The Journal of Neuroscience, vol. 34, no. 3, pp. 726736, 2014.

[43] F. I. Baptista, J. M. Gaspar, A. Cristóvão, P. F. Santos, A. Köfalvi, and A. F. Ambrósio, "Diabetes induces early transient changes in the content of vesicular transporters and no major effects in neurotransmitter release in hippocampus and retina," Brain Research, vol. 1383, pp. 257-269, 2011.

[44] S.-H. Park, J.-W. Park, S.-J. Park et al., "Apoptotic death of photoreceptors in the streptozotocin-induced diabetic rat retina," Diabetologia, vol. 46, no. 9, pp. 1260-1268, 2003.

[45] Y. Aizu, K. Oyanagi, J. Hu, and H. Nakagawa, "Degeneration of retinal neuronal processes and pigment epithelium in the early stage of the streptozotocin-diabetic rats," Neuropathology, vol. 22, no. 3, pp. 161-170, 2002.

[46] S. V. Logvinov, M. B. Plotnikov, A. A. Zhdankina et al., "Morphological changes in retinal neurons in streptozotocininduced diabetes mellitus and their correction with an isobornylphenol derivative," Neuroscience and Behavioral Physiology, vol. 40, no. 7, pp. 779-782, 2010.

[47] M. Lombardo, M. Parravano, G. Lombardo et al., "Adaptive optics imaging of parafoveal cones in type 1 diabetes," Retina, vol. 34, no. 3, pp. 546-557, 2014.

[48] T. S. Kern and B. A. Berkowitz, "Photoreceptors in diabetic retinopathy," Journal of Diabetes Investigation, vol. 6, no. 4, pp. 371-380, 2015.
[49] M. J. Gastinger, A. J. Barber, S. A. Khin, C. S. McRill, T. W. Gardner, and D. W. Marshak, "Abnormal centrifugal axons in streptozotocin-diabetic rat retinas," Investigative Ophthalmology and Visual Science, vol. 42, no. 11, pp. 2679-2685, 2001.

[50] M. J. Gastinger, A. R. Kunselman, E. E. Conboy, S. K. Bronson, and A. J. Barber, "Dendrite remodeling and other abnormalities in the retinal ganglion cells of Ins $2^{\text {Akita }}$ diabetic mice," Investigative Ophthalmology and Visual Science, vol. 49, no. 6, pp. 26352642, 2008.

[51] J. R. Wolter, "Diabetic retinopathy," American Journal of Ophthalmology, vol. 51, no. 5, pp. 1123-1141, 1961.

[52] D. C. Fernandez, L. A. Pasquini, D. Dorfman, H. J. Aldana Marcos, and R. E. Rosenstein, "Early distal axonopathy of the visual pathway in experimental diabetes," The American Journal of Pathology, vol. 180, no. 1, pp. 303-313, 2012.

[53] L. Zhang, M. Inoue, K. Dong, and M. Yamamoto, "Alterations in retrograde axonal transport in optic nerve of type I and type II diabetic rats," Kobe Journal of Medical Sciences, vol. 44, no. 5-6, pp. 205-215, 1998.

[54] S. Bonnin, R. Tadayoni, A. Erginay, P. Massin, and B. Dupas, "Correlation between ganglion cell layer thinning and poor visual function after resolution of diabetic macular edema," Investigative Ophthalmology and Visual Science, vol. 56, no. 2, pp. 978-982, 2015.

[55] B. V. Bui, M. Loeliger, M. Thomas et al., "Investigating structural and biochemical correlates of ganglion cell dysfunction in streptozotocin-induced diabetic rats," Experimental Eye Research, vol. 88, no. 6, pp. 1076-1083, 2009.

[56] J. A. Phipps, E. L. Fletcher, and A. J. Vingrys, "Paired-flash identification of rod and cone dysfunction in the diabetic rat," Investigative Ophthalmology and Visual Science, vol. 45, no. 12, pp. 4592-4600, 2004.

[57] Q. Li, E. Zemel, B. Miller, and I. Perlman, "Early retinal damage in experimental diabetes: electroretinographical and morphological observations," Experimental Eye Research, vol. 74, no. 5, pp. 615-625, 2002.

[58] D. Yonemura, T. Aoki, and K. Tsuzuki, "Electroretinogram in diabetic retinopathy," Archives of Ophthalmology, vol. 68, pp. 1924, 1962.

[59] M. A. Bearse Jr., A. J. Adams, Y. Han et al., "A multifocal electroretinogram model predicting the development of diabetic retinopathy," Progress in Retinal and Eye Research, vol. 25, no. 5, pp. 425-448, 2006.

[60] G. H. Bresnick and M. Palta, "Oscillatory potential amplitudes. Relation to severity of diabetic retinopathy," Archives of Ophthalmology, vol. 105, no. 7, pp. 929-933, 1987.

[61] E. Lakhani, T. Wright, M. Abdolell, and C. Westall, "Multifocal ERG defects associated with insufficient long-term glycemic control in adolescents with type 1 diabetes," Investigative Ophthalmology and Visual Science, vol. 51, no. 10, pp. 5297-5303, 2010.

[62] M. McFarlane, T. Wright, D. Stephens, J. Nilsson, and C. A. Westall, "Blue flash ERG PhNR changes associated with poor long-term glycemic control in adolescents with type 1 diabetes," Investigative Ophthalmology and Visual Science, vol. 53, no. 2, pp. 741-748, 2012.

[63] K. Holopigian, W. Seiple, M. Lorenzo, and R. Carr, "A comparison of photopic and scotopic electroretinographic changes in early diabetic retinopathy," Investigative Ophthalmology and Visual Science, vol. 33, no. 10, pp. 2773-2780, 1992. 
[64] B. E. Wolff, M. A. Bearse, M. E. Schneck et al., "Color vision and neuroretinal function in diabetes," Documenta Ophthalmologica, vol. 130, no. 2, pp. 131-139, 2015.

[65] L. C. O. Andrade, G. S. Souza, E. M. C. B. Lacerda et al., "Influence of retinopathy on the achromatic and chromatic vision of patients with type 2 diabetes," BMC Ophthalmology, vol. 14, article 104, pp. 1471-2415, 2014.

[66] R. Simó and C. Hernández, "Neurodegeneration is an early event in diabetic retinopathy: therapeutic implications," British Journal of Ophthalmology, vol. 96, no. 10, pp. 1285-1290, 2012.

[67] A. Reis, C. Mateus, P. Melo, J. Figueira, J. Cunha-Vaz, and M. Castelo-Branco, "Neuroretinal dysfunction with intact bloodretinal barrier and absent vasculopathy in type 1 diabetes," Diabetes, vol. 63, no. 11, pp. 3926-3937, 2014.

[68] W. Tan, T. Wright, A. Dupuis, E. Lakhani, and C. Westall, "Localizing functional damage in the neural retina of adolescents and young adults with type 1 diabetes," Investigative Ophthalmology and Visual Science, vol. 55, no. 4, pp. 2432-2441, 2014.

[69] M. Chen, T. M. Curtis, and A. W. Stitt, "Advanced glycation end products and diabetic retinopathy," Current Medicinal Chemistry, vol. 20, no. 26, pp. 3234-3240, 2013.

[70] H. Zong, M. Ward, and A. W. Stitt, "AGEs, RAGE, and diabetic retinopathy," Current Diabetes Reports, vol. 11, no. 4, pp. 244252, 2011.

[71] B.-H. Chen, D.-Y. Jiang, and L.-S. Tang, "Advanced glycation end-products induce apoptosis involving the signaling pathways of oxidative stress in bovine retinal pericytes," Life Sciences, vol. 79, no. 11, pp. 1040-1048, 2006.

[72] B. Liu, M. Bhat, A. K. Padival, D. G. Smith, and R. H. Nagaraj, "Effect of dicarbonyl modification of fibronectin on retinal capillary pericytes," Investigative Ophthalmology and Visual Science, vol. 45, no. 6, pp. 1983-1995, 2004.

[73] R. Chibber, P. A. Molinatti, N. Rosatto, B. Lambourne, and E. M. Kohner, "Toxic action of advanced glycation end products on cultured retinal capillary pericytes and endothelial cells: relevance to diabetic retinopathy," Diabetologia, vol. 40, no. 2, pp. 156-164, 1997.

[74] A. W. Stitt, C. McGoldrick, A. Rice-McCaldin et al., "Impaired retinal angiogenesis in diabetes: role of advanced glycation end products and galectin-3," Diabetes, vol. 54, no. 3, pp. 785-794, 2005.

[75] M. Nitti, A. L. Furfaro, N. Traverso et al., "PKC delta and NADPH oxidase in AGE-induced neuronal death," Neuroscience Letters, vol. 416, no. 3, pp. 261-265, 2007.

[76] H. Zong, M. Ward, A. Madden et al., "Hyperglycaemia-induced pro-inflammatory responses by retinal Müller glia are regulated by the receptor for advanced glycation end-products (RAGE)," Diabetologia, vol. 53, no. 12, pp. 2656-2666, 2010.

[77] J. Kim, C.-S. Kim, Y. M. Lee, E. Sohn, K. Jo, and J. S. Kim, "Litsea japonica extract inhibits neuronal apoptosis and the accumulation of advanced glycation end products in the diabetic mouse retina," Molecular Medicine Reports, vol. 12, no. 1, pp. 1075-1081, 2015.

[78] J. Kim, C.-S. Kim, E. Sohn et al., "Aminoguanidine protects against apoptosis of retinal ganglion cells in Zucker diabetic fatty rats," European Review for Medical and Pharmacological Sciences, vol. 18, no. 11, pp. 1573-1578, 2014.

[79] A. Lecleire-Collet, L. H. Tessier, P. Massin et al., "Advanced glycation end products can induce glial reaction and neuronal degeneration in retinal explants," British Journal of Ophthalmology, vol. 89, no. 12, pp. 1631-1633, 2005.
[80] F. Reber, R. Geffarth, M. Kasper et al., "Graded sensitiveness of the various retinal neuron populations on the glyoxal-mediated formation of advanced glycation end products and ways of protection," Graefe's Archive for Clinical and Experimental Ophthalmology, vol. 241, no. 3, pp. 213-225, 2003.

[81] M. Dal Monte, R. Amato, M. Biagioni, M. Cammalleri, and G. Casini, "Neuroprotection as a therapeutic target in diabetic retinopathy: a basic approach," Acta Ophthalmologica, vol. 93, supplement S255, 2015.

[82] E. Lieth, A. J. Barber, B. Xu et al., "Glial reactivity and impaired glutamate metabolism in short-term experimental diabetic retinopathy. Penn State Retina Research Group," Diabetes, vol. 47, no. 5, pp. 815-820, 1998.

[83] E. Lieth, K. F. LaNoue, D. A. Antonetti, M. Ratz, and The Penn State Retina Research Group, "Diabetes reduces glutamate oxidation and glutamine synthesis in the retina," Experimental Eye Research, vol. 70, no. 6, pp. 723-730, 2000.

[84] R. A. Kowluru, R. L. Engerman, G. L. Case, and T. S. Kern, "Retinal glutamate in diabetes and effect of antioxidants," Neurochemistry International, vol. 38, no. 5, pp. 385-390, 2001.

[85] Y.-K. Ng, X.-X. Zeng, and E.-A. Ling, "Expression of glutamate receptors and calcium-binding proteins in the retina of streptozotocin-induced diabetic rats," Brain Research, vol. 1018, no. 1, pp. 66-72, 2004.

[86] A. F. Castilho, J. T. Liberal, F. I. Baptista, J. M. Gaspar, A. L. Carvalho, and A. F. Ambrósio, "Elevated glucose concentration changes the content and cellular localization of AMPA receptors in the retina but not in the hippocampus," Neuroscience, vol. 219, pp. 23-32, 2012.

[87] A. R. Santiago, S. C. Rosa, P. F. Santos, A. J. Cristóvão, A. J. Barber, and A. F. Ambrósio, "Elevated glucose changes the expression of ionotropic glutamate receptor subunits and impairs calcium homeostasis in retinal neural cells," Investigative Ophthalmology and Visual Science, vol. 47, no. 9, pp. 41304137, 2006.

[88] A. R. Santiago, J. M. Gaspar, F. I. Baptista et al., "Diabetes changes the levels of ionotropic glutamate receptors in the rat retina," Molecular Vision, vol. 15, pp. 1620-1630, 2009.

[89] J. Ambati, K. V. Chalam, D. K. Chawala et al., "Elevated $\gamma$ aminobutyric acid, glutamate, and vascular endothelial growth factor levels in the vitreous of patients with proliferative diabetic retinopathy," Archives of Ophthalmology, vol. 115, no. 9, pp. 11611166, 1997.

[90] M.-J. Lu, J. S. Pulido, C. A. McCannel et al., "Detection of elevated signaling amino acids in human diabetic vitreous by rapid capillary electrophoresis," Experimental Diabesity Research, vol. 2007, Article ID 39765, 6 pages, 2007.

[91] A. R. Santiago, J. M. Hughes, W. Kamphuis, R. O. Schlingemann, and A. F. Ambrósio, "Diabetes changes ionotropic glutamate receptor subunit expression level in the human retina," Brain Research, vol. 1198, pp. 153-159, 2008.

[92] Q. Li and D. G. Puro, "Diabetes-induced dysfunction of the glutamate transporter in retinal Müller cells," Investigative Ophthalmology and Visual Science, vol. 43, no. 9, pp. 3109-3116, 2002.

[93] K. H. Gabbay, "The sorbitol pathway and the complications of diabetes," The New England Journal of Medicine, vol. 288, no. 16, pp. 831-836, 1973.

[94] I. G. Obrosova and P. F. Kador, "Aldose reductase/polyol inhibitors for diabetic retinopathy," Current Pharmaceutical Biotechnology, vol. 12, no. 3, pp. 373-385, 2011. 
[95] Z. Dagher, Y. S. Park, V. Asnaghi, T. Hoehn, C. Gerhardinger, and M. Lorenzi, "Studies of rat and human retinas predict a role for the polyol pathway in human diabetic retinopathy," Diabetes, vol. 53, no. 9, pp. 2404-2411, 2004.

[96] C. A. Lee, G. Li, M. D. Patel et al., "Diabetes-induced impairment in visual function in mice: contributions of p38 MAPK, RAGE, leukocytes, and aldose reductase," Investigative Ophthalmology and Visual Science, vol. 55, no. 5, pp. 2904-2910, 2014.

[97] M. Lorenzi, "The polyol pathway as a mechanism for diabetic retinopathy: attractive, elusive, and resilient," Experimental Diabetes Research, vol. 2007, Article ID 61038, 10 pages, 2007.

[98] V. R. Drel, W. Xu, J. Zhang et al., "Poly(ADP-ribose)polymerase inhibition counteracts cataract formation and early retinal changes in streptozotocin-diabetic rats," Investigative Ophthalmology and Visual Science, vol. 50, no. 4, pp. 1778-1790, 2009.

[99] L. Zheng, C. Szabó, and T. S. Kern, "Poly(ADP-ribose) polymerase is involved in the development of diabetic retinopathy via regulation of nuclear factor- $\kappa \mathrm{B}$," Diabetes, vol. 53 , no. 11, pp. 2960-2967, 2004.

[100] I. G. Obrosova and U. A. Julius, "Role for poly(ADP-ribose) polymerase activation in diabetic nephropathy, neuropathy and retinopathy," Current Vascular Pharmacology, vol. 3, no. 3, pp. 267-283, 2005.

[101] G. Mohammad, M. M. Siddiquei, and A. M. Abu El-Asrar, "Poly (ADP-Ribose) polymerase mediates diabetes-induced retinal neuropathy," Mediators of Inflammation, vol. 2013, Article ID 510451, 10 pages, 2013.

[102] S. Z. Safi, R. Qvist, S. Kumar, K. Batumalaie, and I. S. B. Ismail, "Molecular mechanisms of diabetic retinopathy, general preventive strategies, and novel therapeutic targets," BioMed Research International, vol. 2014, Article ID 801269, 18 pages, 2014.

[103] M. Nakamura, A. J. Barber, D. A. Antonetti et al., "Excessive hexosamines block the neuroprotective effect of insulin and induce apoptosis in retinal neurons," The Journal of Biological Chemistry, vol. 276, no. 47, pp. 43748-43755, 2001.

[104] T. E. Fox, M. M. Young, M. M. Pedersen, S. GiambuzziTussey, M. Kester, and T. W. Gardner, "Insulin signaling in retinal neurons is regulated within cholesterol-enriched membrane microdomains," American Journal of PhysiologyEndocrinology and Metabolism, vol. 300, no. 3, pp. E600-E609, 2011.

[105] T. Behl, I. Kaur, and A. Kotwani, "Implication of oxidative stress in progression of diabetic retinopathy," Survey of Ophthalmology, vol. 61, no. 2, pp. 187-196, 2016.

[106] D. M. van Reyk, M. C. Gillies, and M. J. Davies, “The retina: oxidative stress and diabetes," Redox Report, vol. 8, no. 4, pp. 187-192, 2003.

[107] M. Sasaki, Y. Ozawa, T. Kurihara et al., "Neurodegenerative influence of oxidative stress in the retina of a murine model of diabetes," Diabetologia, vol. 53, no. 5, pp. 971-979, 2010.

[108] L. Zheng and T. S. Kern, "Role of nitric oxide, superoxide, peroxynitrite and PARP in diabetic retinopathy," Frontiers in Bioscience, vol. 14, no. 10, pp. 3974-3987, 2009.

[109] R. A. Kowluru, "Diabetes-induced elevations in retinal oxidative stress, protein kinase $\mathrm{C}$ and nitric oxide are interrelated," Acta Diabetologica, vol. 38, no. 4, pp. 179-185, 2001.

[110] M. Coucha, S. L. Elshaer, W. S. Eldahshan, B. A. Mysona, and A. B. El-Remessy, "Molecular mechanisms of diabetic retinopathy: potential therapeutic targets," Middle East African Journal of Ophthalmology, vol. 22, no. 2, pp. 135-144, 2015.
[111] C. Piperi, A. Goumenos, C. Adamopoulos, and A. G. Papavassiliou, "AGE/RAGE signalling regulation by miRNAs: associations with diabetic complications and therapeutic potential," International Journal of Biochemistry and Cell Biology, vol. 60, pp. 197201, 2015.

[112] M. J. Giese and R. C. Speth, "The ocular renin-angiotensin system: a therapeutic target for the treatment of ocular disease," Pharmacology and Therapeutics, vol. 142, no. 1, pp. 11-32, 2014.

[113] J. L. Wilkinson-Berka, "Angiotensin and diabetic retinopathy," International Journal of Biochemistry and Cell Biology, vol. 38, no. 5-6, pp. 752-765, 2006.

[114] J. L. Wilkinson-Berka, A. Agrotis, and D. Deliyanti, "The retinal renin-angiotensin system: roles of angiotensin II and aldosterone," Peptides, vol. 36, no. 1, pp. 142-150, 2012.

[115] B. V. Bui, J. A. Armitage, M. Tolcos, M. E. Cooper, and A. J. Vingrys, "ACE inhibition salvages the visual loss caused by diabetes," Diabetologia, vol. 46, no. 3, pp. 401-408, 2003.

[116] T. Kurihara, Y. Ozawa, N. Nagai et al., "Angiotensin II type 1 receptor signaling contributes to synaptophysin degradation and neuronal dysfunction in the diabetic retina," Diabetes, vol. 57, no. 8, pp. 2191-2198, 2008.

[117] T. Sugiyama, T. Okuno, M. Fukuhara et al., "Angiotensin II receptor blocker inhibits abnormal accumulation of advanced glycation end products and retinal damage in a rat model of type 2 diabetes," Experimental Eye Research, vol. 85, no. 3, pp. 406-412, 2007.

[118] K. C. Silva, M. A. B. Rosales, S. K. Biswas, J. B. L. De Faria, and J. M. L. De Faria, "Diabetic retinal neurodegeneration is associated with mitochondrial oxidative stress and is improved by an angiotensin receptor blocker in a model combining hypertension and diabetes," Diabetes, vol. 58 , no. 6, pp. $1382-$ 1390, 2009.

[119] A. M. Joussen, V. Poulaki, M. L. Le et al., "A central role for inflammation in the pathogenesis of diabetic retinopathy," The FASEB Journal, vol. 18, no. 12, pp. 1450-1452, 2004.

[120] Y. Yu, H. Chen, and S. B. Su, "Neuroinflammatory responses in diabetic retinopathy," Journal of Neuroinflammation, vol. 12, article 141, 2015.

[121] S. B. Beynon and F. R. Walker, "Microglial activation in the injured and healthy brain: what are we really talking about? Practical and theoretical issues associated with the measurement of changes in microglial morphology," Neuroscience, vol. 225, pp. 162-171, 2012.

[122] E. Polazzi and B. Monti, "Microglia and neuroprotection: from in vitro studies to therapeutic applications," Progress in Neurobiology, vol. 92, no. 3, pp. 293-315, 2010.

[123] M. Mizutani, C. Gerhardinger, and M. Lorenzi, "Muller cell changes in human diabetic retinopathy," Diabetes, vol. 47, no. 3, pp. 445-449, 1998.

[124] X. Liu, F. Ye, H. Xiong et al., "IL-1 $\beta$ Induces IL-6 production in retinal Müller cells predominantly through the activation of P38 MAPK/NF- $\kappa$ B signaling pathway," Experimental Cell Research, vol. 331, no. 1, pp. 223-231, 2015.

[125] C. Gerhardinger, M. B. Costa, M. C. Coulombe, I. Toth, T. Hoehn, and P. Grosu, "Expression of acute-phase response proteins in retinal Muller cells in diabetes," Investigative Ophthalmology and Visual Science, vol. 46, no. 1, pp. 349-357, 2005.

[126] T. C. Frank-Cannon, L. T. Alto, F. E. McAlpine, and M. G. Tansey, "Does neuroinflammation fan the flame in neurodegenerative diseases?" Molecular Neurodegeneration, vol. 4, article 47, pp. 1750-1326, 2009. 
[127] M. E. Lull and M. L. Block, "Microglial activation and chronic neurodegeneration," Neurotherapeutics, vol. 7, no. 4, pp. 354$365,2010$.

[128] S. X. Zhang, E. Sanders, S. J. Fliesler, and J. J. Wang, "Endoplasmic reticulum stress and the unfolded protein responses in retinal degeneration," Experimental Eye Research, vol. 125, pp. 30-40, 2014.

[129] M. Shimazawa, A. Miwa, Y. Ito, K. Tsuruma, M. Aihara, and H. Hara, "Involvement of endoplasmic reticulum stress in optic nerve degeneration following N-methyl-D-aspartate-induced retinal damage in mice," Journal of Neuroscience Research, vol. 90, no. 10, pp. 1960-1969, 2012.

[130] L. P. Yang, L. M. Wu, D. M. Wang et al., "Role of endoplasmic reticulum stress in the loss of retinal ganglion cells in diabetic retinopathy," Neural Regeneration Research, vol. 8, no. 33, pp. 3148-3158, 2013.

[131] C. E. N. Reiter, L. Sandirasegarane, E. B. Wolpert et al., "Characterization of insulin signaling in rat retina in vivo and ex vivo," American Journal of Physiology-Endocrinology and Metabolism, vol. 285, no. 4, pp. E763-E774, 2003.

[132] X. Wu, C. E. N. Reiter, D. A. Antonetti, S. R. Kimball, L. S. Jefferson, and T. W. Gardner, "Insulin promotes rat retinal neuronal cell survival in a p70S6K-dependent manner," Journal of Biological Chemistry, vol. 279, no. 10, pp. 9167-9175, 2004.

[133] A. J. Barber, M. Nakamura, E. B. Wolpert et al., "Insulin rescues retinal neurons from apoptosis by a phosphatidylinositol 3kinase/Akt-mediated mechanism that reduces the activation of caspase-3," Journal of Biological Chemistry, vol. 276, no. 35, pp. 32814-32821, 2001.

[134] C. E. N. Reiter, X. Wu, L. Sandirasegarane et al., "Diabetes reduces basal retinal insulin receptor signaling: reversal with systemic and local insulin," Diabetes, vol. 55, no. 4, pp. 11481156, 2006.

[135] C. Gerhardinger, K. D. McClure, G. Romeo, F. Podestà, and M. Lorenzi, "IGF-I mRNA and signaling in the diabetic retina," Diabetes, vol. 50, no. 1, pp. 175-183, 2001.

[136] A. Kummer, B. E. Pulford, D. N. Ishii, and G. M. Seigel, "Des(13)IGF-1 treatment normalizes type 1 IGF receptor and phosphoAkt (Thr 308) immunoreactivity in predegenerative retina of diabetic rats," Experimental Diabesity Research, vol. 4, no. 1, pp. 45-57, 2003.

[137] C. J. Barnstable and J. Tombran-Tink, "Neuroprotective and antiangiogenic actions of PEDF in the eye: molecular targets and therapeutic potential," Progress in Retinal and Eye Research, vol. 23, no. 5, pp. 561-577, 2004.

[138] B. Zheng, T. Li, H. Chen, X. Xu, and Z. Zheng, "Correlation between ficolin-3 and vascular endothelial growth factor-topigment epithelium-derived factor ratio in the vitreous of eyes with proliferative diabetic retinopathy," American Journal of Ophthalmology, vol. 152, no. 6, pp. 1039-1043, 2011.

[139] X. Shen, Y. Zhong, B. Xie, Y. Cheng, and Q. Jiao, "Pigment epithelium derived factor as an anti-inflammatory factor against decrease of glutamine synthetase expression in retinal Müller cells under high glucose conditions," Graefe's Archive for Clinical and Experimental Ophthalmology, vol. 248, no. 8, pp. 1127-1136, 2010.

[140] B. Xie, Q. Jiao, Y. Cheng, Y. Zhong, and X. Shen, "Effect of pigment epithelium-derived factor on glutamate uptake in retinal Müller cells under high-glucose conditions," Investigative Ophthalmology and Visual Science, vol. 53, no. 2, pp. 1023-1032, 2012.
[141] A. M. Abu El-Asrar, G. Mohammad, G. De Hertogh et al., "Neurotrophins and neurotrophin receptors in proliferative diabetic retinopathy," PLoS ONE, vol. 8, no. 6, Article ID e65472, 2013.

[142] M. M. H. Al-Gayyar, S. Matragoon, B. A. Pillai, T. K. Ali, M. A. Abdelsaid, and A. B. El-Remessy, "Epicatechin blocks pro-nerve growth factor (proNGF)-mediated retinal neurodegeneration via inhibition of $\mathrm{p} 75$ neurotrophin receptor proNGF expression in a rat model of diabetes," Diabetologia, vol. 54 , no. 3, pp. 669680, 2011.

[143] B. A. Mysona, M. M. H. Al-Gayyar, S. Matragoon et al., "Modulation of $\mathrm{p} 75^{\mathrm{NTR}}$ prevents diabetes- and proNGF-induced retinal inflammation and blood-retina barrier breakdown in mice and rats," Diabetologia, vol. 56, no. 10, pp. 2329-2339, 2013.

[144] B. A. Mysona, A. Y. Shanab, S. L. Elshaer, and A. B. El-Remessy, "Nerve growth factor in diabetic retinopathy: beyond neurons," Expert Review of Ophthalmology, vol. 9, no. 2, pp. 99-107, 2014.

[145] M. S. Ola, M. I. Nawaz, A. A. El-Asrar, M. Abouammoh, and A. S. Alhomida, "Reduced levels of brain derived neurotrophic factor (BDNF) in the serum of diabetic retinopathy patients and in the retina of diabetic rats," Cellular and Molecular Neurobiology, vol. 33, no. 3, pp. 359-367, 2013.

[146] G. I. Liou, Y. Fei, N. S. Peachey et al., "Early onset photoreceptor abnormalities induced by targeted disruption of the interphotoreceptor retinoid-binding protein gene," Journal of Neuroscience, vol. 18, no. 12, pp. 4511-4520, 1998.

[147] M. García-Ramírez, F. Canals, C. Hernández et al., "Proteomic analysis of human vitreous fluid by fluorescence-based difference gel electrophoresis (DIGE): a new strategy for identifying potential candidates in the pathogenesis of proliferative diabetic retinopathy," Diabetologia, vol. 50, no. 6, pp. 1294-1303, 2007.

[148] M. Garcia-Ramírez, C. Hernández, M. Villarroel et al., "Interphotoreceptor retinoid-binding protein (IRBP) is downregulated at early stages of diabetic retinopathy," Diabetologia, vol. 52, no. 12, pp. 2633-2641, 2009.

[149] G. Casini, E. Catalani, M. Dal Monte, and P. Bagnoli, "Functional aspects of the somatostatinergic system in the retina and the potential therapeutic role of somatostatin in retinal disease," Histology and Histopathology, vol. 20, no. 2, pp. 615-632, 2005.

[150] E. Carrasco, C. Hernández, A. Miralles, P. Huguet, J. Farrés, and R. Simó, "Lower somatostatin expression is an early event in diabetic retinopathy and is associated with retinal neurodegeneration," Diabetes Care, vol. 30, no. 11, pp. 29022908, 2007.

[151] C. Hernández, E. Carrasco, R. Casamitjana, R. Deulofeu, J. García-Arumí, and R. Simó, "Somatostatin molecular variants in the vitreous fluid: a comparative study between diabetic patients with proliferative diabetic retinopathy and nondiabetic control subjects," Diabetes Care, vol. 28, no. 8, pp. 1941-1947, 2005.

[152] R. Simó, A. Lecube, L. Sararols et al., "Deficit of somatostatinlike immunoreactivity in the vitreous fluid of diabetic patients: possible role in the development of proliferative diabetic retinopathy," Diabetes Care, vol. 25, no. 12, pp. 2282-2286, 2002.

[153] R. Simó, E. Carrasco, A. Fonollosa, J. García-Arumí, R. Casamitjana, and C. Hernández, "Deficit of somatostatin in the vitreous fluid of patients with diabetic macular edema," Diabetes Care, vol. 30, no. 3, pp. 725-727, 2007.

[154] E. Catalani, D. Cervia, D. Martini et al., "Changes in neuronal response to ischemia in retinas with genetic alterations of somatostatin receptor expression," European Journal of Neuroscience, vol. 25, no. 5, pp. 1447-1459, 2007. 
[155] D. Cervia, D. Martini, C. Ristori et al., "Modulation of the neuronal response to ischaemia by somatostatin analogues in wildtype and knock-out mouse retinas," Journal of Neurochemistry, vol. 106, no. 5, pp. 2224-2235, 2008.

[156] A. D’Alessandro, D. Cervia, E. Catalani, F. Gevi, L. Zolla, and G. Casini, "Protective effects of the neuropeptides PACAP, substance $P$ and the somatostatin analogue octreotide in retinal ischemia: a metabolomic analysis," Molecular BioSystems, vol. 10, no. 6, pp. 1290-1304, 2014.

[157] C. Hernández, M. García-Ramírez, L. Corraliza et al., “Topical administration of somatostatin prevents retinal neurodegeneration in experimental diabetes," Diabetes, vol. 62, no. 7, pp. 25692578, 2013.

[158] C. Iadecola and J. Anrather, "Stroke research at a crossroad: asking the brain for directions," Nature Neuroscience, vol. 14, no. 11, pp. 1363-1368, 2011.

[159] D. Cervia, E. Catalani, M. Dal Monte, and G. Casini, "Vascular endothelial growth factor in the ischemic retina and its regulation by somatostatin," Journal of Neurochemistry, vol. 120, no. 5, pp. 818-829, 2012.

[160] A. R. Cervantes-Villagrana, J. Garcia-Román, C. GonzlezEspinosa, and M. Lamas, "Pharmacological inhibition of nmethyl d-aspartate receptor promotes secretion of vascular endothelial growth factor in müller cells: effects of hyperglycemia and hypoxia," Current Eye Research, vol. 35, no. 8, pp. 733-741, 2010.

[161] J. Kusari, S. X. Zhou, E. Padillo, K. G. Clarke, and D. W. Gil, "Inhibition of vitreoretinal VEGF elevation and blood-retinal barrier breakdown in streptozotocin-induced diabetic rats by brimonidine," Investigative Ophthalmology and Visual Science, vol. 51, no. 2, pp. 1044-1051, 2010.

[162] A. Ebneter, G. Chidlow, J. P. M. Wood, and R. J. Casson, "Protection of retinal ganglion cells and the optic nerve during short-term hyperglycemia in experimental glaucoma," Archives of Ophthalmology, vol. 129, no. 10, pp. 1337-1344, 2011.

[163] M. Saint-Geniez, A. S. R. Maharaj, T. E. Walshe et al., "Endogenous VEGF is required for visual function: evidence for a survival role on Müller cells and photoreceptors," PLoS ONE, vol. 3, no. 11, Article ID e3554, 2008.

[164] R. H. Foxton, A. Finkelstein, S. Vijay et al., "VEGF-A is necessary and sufficient for retinal neuroprotection in models of experimental glaucoma," The American Journal of Pathology, vol. 182, no. 4, pp. 1379-1390, 2013.

[165] M. R. Romano, F. Biagioni, G. Besozzi et al., "Effects of bevacizumab on neuronal viability of retinal ganglion cells in rats," Brain Research, vol. 1478, pp. 55-63, 2012.

[166] M. Azzouz, G. S. Ralph, E. Storkebaum et al., "VEGF delivery with retrogradely transported lentivector prolongs survival in a mouse ALS model," Nature, vol. 429, no. 6990, pp. 413-417, 2004.

[167] G. Casini, M. Dal Monte, I. Fornaciari, L. Filippi, and P. Bagnoli, "The $\beta$-adrenergic system as a possible new target for pharmacologic treatment of neovascular retinal diseases," Progress in Retinal and Eye Research, vol. 42, pp. 103-129, 2014.

[168] M. A. Abdelsaid, B. A. Pillai, S. Matragoon, R. Prakash, M. Al-Shabrawey, and A. B. El-Remessy, "Early intervention of tyrosine nitration prevents vaso-obliteration and neovascularization in ischemic retinopathy," Journal of Pharmacology and Experimental Therapeutics, vol. 332, no. 1, pp. 125-134, 2010.

[169] A. B. El-Remessy, M. Bartoli, D. H. Platt, D. Fulton, and R. B. Caldwell, "Oxidative stress inactivates VEGF survival signaling in retinal endothelial cells via PI 3-kinase tyrosine nitration," Journal of Cell Science, vol. 118, no. 1, pp. 243-252, 2005.

[170] N. Beazley-Long, J. Hua, T. Jehle et al., "VEGF-A165b is an endogenous neuroprotective splice isoform of vascular endothelial growth factor a in vivo and in vitro," The American Journal of Pathology, vol. 183, no. 3, pp. 918-929, 2013.

[171] R. M. Perrin, O. Konopatskaya, Y. Qiu, S. Harper, D. O. Bates, and A. J. Churchill, "Diabetic retinopathy is associated with a switch in splicing from anti- to pro-angiogenic isoforms of vascular endothelial growth factor," Diabetologia, vol. 48, no. 11, pp. 2422-2427, 2005.

[172] J. S. Ng, M. A. Bearse Jr., M. E. Schneck, S. Barez, and A. J. Adams, "Local diabetic retinopathy prediction by multifocal ERG delays over 3 years," Investigative Ophthalmology and Visual Science, vol. 49, no. 4, pp. 1622-1628, 2008.

[173] Y. Han, M. E. Schneck, M. A. Bearse Jr. et al., "Formulation and evaluation of a predictive model to identify the sites of future diabetic retinopathy," Investigative Ophthalmology and Visual Science, vol. 45, no. 11, pp. 4106-4112, 2004.

[174] W. W. Harrison, M. A. Bearse Jr., J. S. Ng et al., "Multifocal electroretinograms predict onset of diabetic retinopathy in adult patients with diabetes," Investigative Ophthalmology and Visual Science, vol. 52, no. 2, pp. 772-777, 2011.

[175] S. Vujosevic, S. Bini, G. Midena, M. Berton, E. Pilotto, and E. Midena, "Hyperreflective intraretinal spots in diabetics without and with nonproliferative diabetic retinopathy: an in vivo study using spectral domain OCT,' Journal of Diabetes Research, vol. 2013, Article ID 491835, 5 pages, 2013.

[176] M. G. Field, D. Yang, Z.-M. Bian, H. R. Petty, and V. M. Elner, "Retinal flavoprotein fluorescence correlates with mitochondrial stress, apoptosis, and chemokine expression," Experimental Eye Research, vol. 93, no. 4, pp. 548-555, 2011.

[177] M. G. Field, V. M. Elner, D. G. Puro et al., "Rapid, noninvasive detection of diabetes-induced retinal metabolic stress," Archives of Ophthalmology, vol. 126, no. 7, pp. 934-938, 2008.

[178] L. P. Aiello, "Targeting intraocular neovascularization and edema-one drop at a time," The New England Journal of Medicine, vol. 359, no. 9, pp. 967-969, 2008.

[179] M. Dal Monte, G. Casini, G. la Marca, B. Isacchi, L. Filippi, and P. Bagnoli, "Eye drop propranolol administration promotes the recovery of oxygen-induced retinopathy in mice," Experimental Eye Research, vol. 111, pp. 27-35, 2013.

[180] A. Lambiase, F. Mantelli, and S. Bonini, "Nerve growth factor eye drops to treat glaucoma," Drug News and Perspectives, vol. 23, no. 6, pp. 361-367, 2010.

[181] M. Saylor, L. K. McLoon, A. R. Harrison, and M. S. Lee, "Experimental and clinical evidence for brimonidine as an optic nerve and retinal neuroprotective agent: an evidence-based review," Archives of Ophthalmology, vol. 127, no. 4, pp. 402-406, 2009.

[182] N. Cheung, P. Mitchell, and T. Y. Wong, "Diabetic retinopathy," The Lancet, vol. 376, no. 9735, pp. 124-136, 2010.

[183] A. Robin and D. S. Grover, "Compliance and adherence in glaucoma management," Indian Journal of Ophthalmology, vol. 59, supplement 1, pp. S93-S96, 2011.

[184] P. E. Fort, M. K. Losiewicz, C. E. N. Reiter et al., "Differential roles of hyperglycemia and hypoinsulinemia in diabetes induced retinal cell death: evidence for retinal insulin resistance," PLoS ONE, vol. 6, no. 10, Article ID e26498, 2011.

[185] G. P. Misra, R. S. J. Singh, T. S. Aleman, S. G. Jacobson, T. W. Gardner, and T. L. Lowe, "Subconjunctivally implantable 
hydrogels with degradable and thermoresponsive properties for sustained release of insulin to the retina," Biomaterials, vol. 30, no. 33, pp. 6541-6547, 2009.

[186] F. Polato and S. P. Becerra, "Pigment epithelium-derived factor, a protective factor for photoreceptors in Vivo," Advances in Experimental Medicine and Biology, vol. 854, pp. 699-706, 2016.

[187] Y. Yoshida, S.-I. Yamagishi, T. Matsui et al., "Protective role of pigment epithelium-derived factor (PEDF) in early phase of experimental diabetic retinopathy," Diabetes/Metabolism Research and Reviews, vol. 25, no. 7, pp. 678-686, 2009.

[188] J. Tombran-Tink, "PEDF in angiogenic eye diseases," Current Molecular Medicine, vol. 10, no. 3, pp. 267-278, 2010.

[189] H. Liu, J.-G. Ren, W. L. Cooper, C. E. Hawkins, M. R. Cowan, and P. Y. Tong, "Identification of the antivasopermeability effect of pigment epithelium-derived factor and its active site," Proceedings of the National Academy of Sciences of the United States of America, vol. 101, no. 17, pp. 6605-6610, 2004.

[190] M. Elahy, S. Baindur-Hudson, V. F. Cruzat, P. Newsholme, and C. R. Dass, "Mechanisms of PEDF-mediated protection against reactive oxygen species damage in diabetic retinopathy and neuropathy," Journal of Endocrinology, vol. 222, no. 3, pp. R129R139, 2014.

[191] Y. Wang, Q. Lu, S. Gao et al., "Pigment epithelium-derived factor regulates glutamine synthetase and l-glutamate/l-aspartate transporter in retinas with oxygen-induced retinopathy," Current Eye Research, vol. 40, no. 12, pp. 1232-1244, 2015.

[192] R. Longeras, K. Farjo, M. Ihnat, and J.-X. Ma, "A PEDFderived peptide inhibits retinal neovascularization and blocks mobilization of bone marrow-derived endothelial progenitor cells," Experimental Diabetes Research, vol. 2012, Article ID 518426, 11 pages, 2012.

[193] Y. Liu, L. F. Leo, C. McGregor, A. Grivitishvili, C. J. Barnstable, and J. Tombran-Tink, "Pigment epithelium-derived factor (PEDF) peptide eye drops reduce inflammation, cell death and vascular leakage in diabetic retinopathy in Ins2 ${ }^{\text {Akita }}$ mice," Molecular Medicine, vol. 18, pp. 1387-1401, 2012.

[194] V. Vigneswara, M. Esmaeili, L. Deer, M. Berry, A. Logan, and Z. Ahmed, "Eye drop delivery of pigment epithelium-derived factor-34 promotes retinal ganglion cell neuroprotection and axon regeneration," Molecular and Cellular Neuroscience, vol. 68, pp. 212-221, 2015.

[195] D. Cervia and G. Casini, “The neuropeptide systems and their potential role in the treatment of mammalian retinal ischemia: a developing story," Current Neuropharmacology, vol. 11, no. 1, pp. 95-101, 2013.

[196] M. Dal Monte, C. Petrucci, A. Cozzi, J. P. Allen, and P. Bagnoli, "Somatostatin inhibits potassium-evoked glutamate release by activation of the sst ${ }_{2}$ somatostatin receptor in the mouse retina," Naunyn-Schmiedeberg's Archives of Pharmacology, vol. 367, no. 2, pp. 188-192, 2003.

[197] T. Atlasz, K. Szabadfi, P. Kiss et al., "Pituitary adenylate cyclase activating polypeptide in the retina: focus on the retinoprotective effects," Annals of the New York Academy of Sciences, vol. 1200, pp. 128-139, 2010.

[198] T. Seki, H. Itoh, T. Nakamachi et al., "Suppression of rat retinal ganglion cell death by PACAP following transient ischemia induced by high intraocular pressure," Journal of Molecular Neuroscience, vol. 43, no. 1, pp. 30-34, 2011.

[199] C. Hlscher, "Potential role of glucagon-like peptide-1 (GLP-1) in neuroprotection," CNS Drugs, vol. 26, no. 10, pp. 871-882, 2012.

[200] Y. Zhang, J. Zhang, Q. Wang et al., "Intravitreal injection of exendin-4 analogue protects retinal cells in early diabetic rats,"
Investigative Ophthalmology and Visual Science, vol. 52, no. 1, pp. 278-285, 2011.

[201] Y. Fan, K. Liu, Q. Wang, Y. Ruan, Y. Zhang, and W. Ye, "Exendin4 protects retinal cells from early diabetes in Goto-Kakizaki rats by increasing the $\mathrm{Bcl}-2 / \mathrm{Bax}$ and $\mathrm{Bcl}-\mathrm{xL} / \mathrm{Bax}$ ratios and reducing reactive gliosis," Molecular Vision, vol. 20, pp. 1557-1568, 2014.

[202] C. Hernandez, P. Bogdanov, L. Corraliza et al., “Topical administration of GLP-1 receptor agonists prevents retinal neurodegeneration in experimental diabetes," Diabetes, vol. 65, no. 1, pp. 172-187, 2016.

[203] Y. Gong, Z.-P. Chang, R.-T. Ren et al., "Protective effects of adeno-associated virus mediated brain-derived neurotrophic factor expression on retinal ganglion cells in diabetic rats," Cellular and Molecular Neurobiology, vol. 32, no. 3, pp. 467-475, 2012.

[204] B.-A. Berk, S. Vogler, T. Pannicke et al., "Brain-derived neurotrophic factor inhibits osmotic swelling of rat retinal glial (Müller) and bipolar cells by activation of basic fibroblast growth factor signaling," Neuroscience, vol. 295, pp. 175-186, 2015.

[205] H. P. Hammes, H. J. Federoff, and M. Brownlee, "Nerve growth factor prevents both neuroretinal programmed cell death and capillary pathology in experimental diabetes," Molecular Medicine, vol. 1, no. 5, pp. 527-534, 1995.

[206] V. Colafrancesco, M. Coassin, S. Rossi, and L. Aloe, "Effect of eye NGF administration on two animal models of retinal ganglion cells degeneration," Annali dell'Istituto Superiore di Sanita, vol. 47, no. 3, pp. 284-289, 2011.

[207] S. Majumdar and R. Srirangam, "Potential of the bioflavonoids in the prevention/treatment of ocular disorders," Journal of Pharmacy and Pharmacology, vol. 62, no. 8, pp. 951-965, 2010.

[208] B. Kumar, S. K. Gupta, T. C. Nag et al., "Retinal neuroprotective effects of quercetin in streptozotocin-induced diabetic rats," Experimental Eye Research, vol. 125, pp. 193-202, 2014.

[209] F. Ghadiri Soufi, E. Arbabi-Aval, M. Rezaei Kanavi, and H. Ahmadieh, "Anti-inflammatory properties of resveratrol in the retinas of type 2 diabetic rats," Clinical and Experimental Pharmacology and Physiology, vol. 42, no. 1, pp. 63-68, 2015.

[210] F. G. Soufi, M. Vardyani, R. Sheervalilou, M. Mohammadi, and M. H. Somi, "Long-term treatment with resveratrol attenuates oxidative stress pro-inflammatory mediators and apoptosis in streptozotocin-nicotinamide-induced diabetic rats," General Physiology and Biophysics, vol. 31, no. 4, pp. 431-438, 2012.

[211] A. S. Yar, S. Menevse, I. Dogan et al., "Investigation of ocular neovascularization-related genes and oxidative stress in diabetic rat eye tissues after resveratrol treatment," Journal of Medicinal Food, vol. 15, no. 4, pp. 391-398, 2012.

[212] T. Mrudula, P. Suryanarayana, P. N. B. S. Srinivas, and G. B. Reddy, "Effect of curcumin on hyperglycemia-induced vascular endothelial growth factor expression in streptozotocin-induced diabetic rat retina," Biochemical and Biophysical Research Communications, vol. 361, no. 2, pp. 528-532, 2007.

[213] Z.-F. Zuo, Q. Zhang, and X.-Z. Liu, "Protective effects of curcumin on retinal Müller cell in early diabetic rats," International Journal of Ophthalmology, vol. 6, no. 4, pp. 422-424, 2013.

[214] S. K. Gupta, B. Kumar, T. C. Nag et al., "Curcumin prevents experimental diabetic retinopathy in rats through its hypoglycemic, antioxidant, and anti-inflammatory mechanisms," Journal of Ocular Pharmacology and Therapeutics, vol. 27, no. 2, pp. 123-130, 2011. 
[215] B. Kumar, S. K. Gupta, B. P. Srinivasan et al., "Hesperetin rescues retinal oxidative stress, neuroinflammation and apoptosis in diabetic rats," Microvascular Research, vol. 87, pp. 65-74, 2013.

[216] A. S. Ibrahim, M. M. El-Shishtawy, A. Peña Jr., and G. I. Liou, "Genistein attenuates retinal inflammation associated with diabetes by targeting of microglial activation," Molecular Vision, vol. 16, pp. 2033-2042, 2010.

[217] S. A. Elgayar, S. A. Eltony, A. A. Sayed, and M. M. AbdelRouf, "Genistein treatment confers protection against gliopathy and vasculopathy of the diabetic retina in rats," Ultrastructural Pathology, vol. 39, no. 6, pp. 385-394, 2015.

[218] M. Nebbioso, M. Federici, D. Rusciano, M. Evangelista, and N. Pescosolido, "Oxidative stress in preretinopathic diabetes subjects and antioxidants," Diabetes Technology and Therapeutics, vol. 14, no. 3, pp. 257-263, 2012.

[219] K. C. Silva, M. A. B. Rosales, D. E. Hamassaki et al., "Green tea is neuroprotective in diabetic retinopathy," Investigative Ophthalmology and Visual Science, vol. 54, no. 2, pp. 1325-1336, 2013.

[220] R. A. Kowluru, B. Menon, and D. L. Gierhart, "Beneficial effect of zeaxanthin on retinal metabolic abnormalities in diabetic rats," Investigative Ophthalmology and Visual Science, vol. 49, no. 4, pp. 1645-1651, 2008.

[221] R. A. Kowluru, Q. Zhong, J. M. Santos, M. Thandampallayam, D. Putt, and D. L. Gierhart, "Beneficial effects of the nutritional supplements on the development of diabetic retinopathy," Nutrition and Metabolism, vol. 11, no. 1, article 8, 2014.

[222] Age-Related Eye Disease Study 2 Research Group, "Lutein + zeaxanthin and omega-3 fatty acids for age-related macular degeneration: the Age-Related Eye Disease Study 2 (AREDS2) randomized clinical trial," Journal of the American Medical Association, vol. 309, no. 19, pp. 2005-2015, 2013.

[223] R. Simó and C. Hernández, "Neurodegeneration in the diabetic eye: new insights and therapeutic perspectives," Trends in Endocrinology and Metabolism, vol. 25, no. 1, pp. 23-33, 2014.

[224] C. E. Riva, E. Logean, and B. Falsini, "Visually evoked hemodynamical response and assessment of neurovascular coupling in the optic nerve and retina," Progress in Retinal and Eye Research, vol. 24, no. 2, pp. 183-215, 2005.

[225] F. Formaz, C. E. Riva, and M. Geiser, "Diffuse luminance flicker increases retinal vessel diameter in humans," Current Eye Research, vol. 16, no. 12, pp. 1252-1257, 1997.

[226] A. Lecleire-Collet, I. Audo, M. Aout et al., "Evaluation of retinal function and flicker light-induced retinal vascular response in normotensive patients with diabetes without retinopathy," Investigative Ophthalmology and Visual Science, vol. 52, no. 6, pp. 2861-2867, 2011.

[227] T. T. Nguyen, R. Kawasaki, J. J. Wang et al., "Flicker lightinduced retinal vasodilation in diabetes and diabetic retinopathy," Diabetes Care, vol. 32, no. 11, pp. 2075-2080, 2009.

[228] M. Tyrberg, U. Lindblad, A. Melander, M. Lövestam-Adrian, V. Ponjavic, and S. Andréasson, "Electrophysiological studies in newly onset type 2 diabetes without visible vascular retinopathy," Documenta Ophthalmologica, vol. 123, no. 3, pp. 193-198, 2011.

[229] A. Mishra and E. A. Newman, "Inhibition of inducible nitric oxide synthase reverses the loss of functional hyperemia in diabetic retinopathy," Glia, vol. 58, no. 16, pp. 1996-2004, 2010.

[230] S. S. F. Cheung, J. W. C. Leung, A. K. M. Lam et al., "Selective over-expression of endothelin-1 in endothelial cells exacerbates inner retinal edema and neuronal death in ischemic retina," PLoS ONE, vol. 6, no. 10, Article ID e26184, 2011.
[231] M. Tonari, T. Kurimoto, T. Horie, T. Sugiyama, T. Ikeda, and $\mathrm{H}$. Oku, "Blocking endothelin-B receptors rescues retinal ganglion cells from optic nerve injury through suppression of neuroinflammation," Investigative Ophthalmology and Visual Science, vol. 53, no. 7, pp. 3490-3500, 2012.

[232] A. Z. Minton, N. R. Phatak, D. L. Stankowska et al., "Endothelin $B$ receptors contribute to retinal ganglion cell loss in a rat model of glaucoma," PLoS ONE, vol. 7, no. 8, Article ID e43199, 2012.

[233] X.-S. Mi, X. Zhang, Q. Feng, A. C. Y. Lo, S. K. Chung, and K.-F. So, "Progressive retinal degeneration in transgenic mice with overexpression of endothelin-1 in vascular endothelial cells," Investigative Ophthalmology and Visual Science, vol. 53, no. 8, pp. 4842-4851, 2012.

[234] J. C. Chou, S. D. Rollins, M. Ye, D. Batlle, and A. A. Fawzi, "Endothelin receptor-a antagonist attenuates retinal vascular and neuroretinal pathology in diabetic mice," Investigative Ophthalmology and Visual Science, vol. 55, no. 4, pp. 2516-2525, 2014.

[235] J. Kusari, S. Zhou, E. Padillo, K. G. Clarke, and D. W. Gil, “Effect of memantine on neuroretinal function and retinal vascular changes of streptozotocin-induced diabetic rats," Investigative Ophthalmology and Visual Science, vol. 48, no. 11, pp. 5152-5159, 2007.

[236] D. F. Sena and K. Lindsley, "Neuroprotection for treatment of glaucoma in adults," Cochrane Database Of Systematic Reviews, vol. 2, Article ID CD006539, 2013.

[237] S. A. Jayakody, A. Gonzalez-Cordero, R. R. Ali, and R. A. Pearson, "Cellular strategies for retinal repair by photoreceptor replacement," Progress in Retinal and Eye Research, vol. 46, pp. 31-66, 2015.

[238] D. Ruminski, B. L. Sikorski, D. Bukowska et al., "OCT angiography by absolute intensity difference applied to normal and diseased human retinas," Biomedical Optics Express, vol. 6, no. 8, pp. 2738-2754, 2015.

[239] T. Bek, "Fine structure in diabetic retinopathy lesions as observed by adaptive optics imaging. A qualitative study," Acta Ophthalmologica, vol. 92, no. 8, pp. 753-758, 2014.

[240] S. Arichika, A. Uji, T. Murakami et al., "Retinal hemorheologic characterization of early-stage diabetic retinopathy using adaptive optics scanning laser ophthalmoscopy," Investigative Ophthalmology and Visual Science, vol. 55, no. 12, pp. 8513-8522, 2014.

[241] R. Gaudana, J. Jwala, S. H. S. Boddu, and A. K. Mitra, "Recent perspectives in ocular drug delivery," Pharmaceutical Research, vol. 26, no. 5, pp. 1197-1216, 2009. 


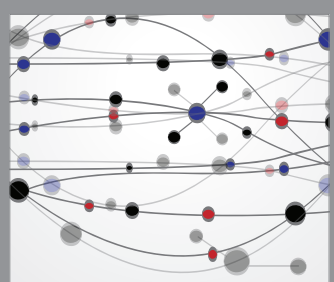

The Scientific World Journal
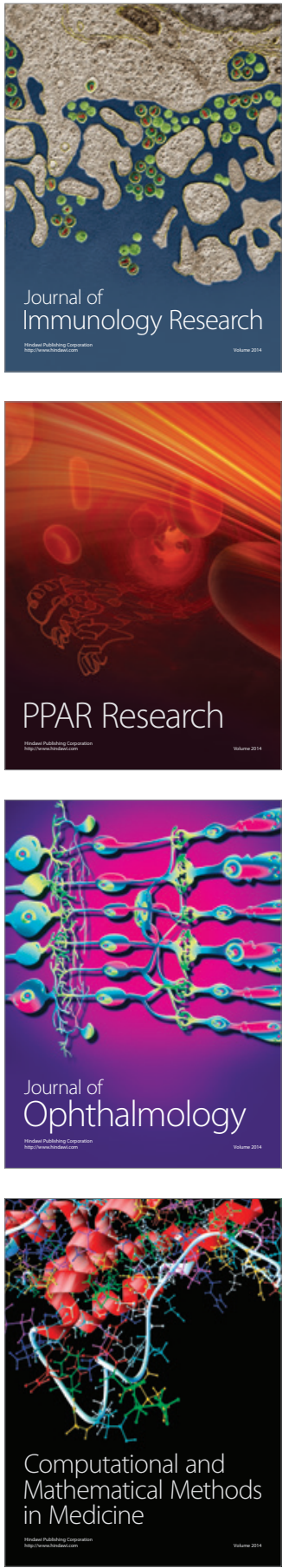

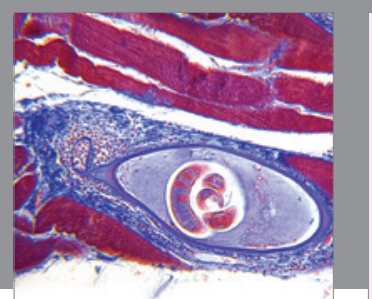

Gastroenterology Research and Practice

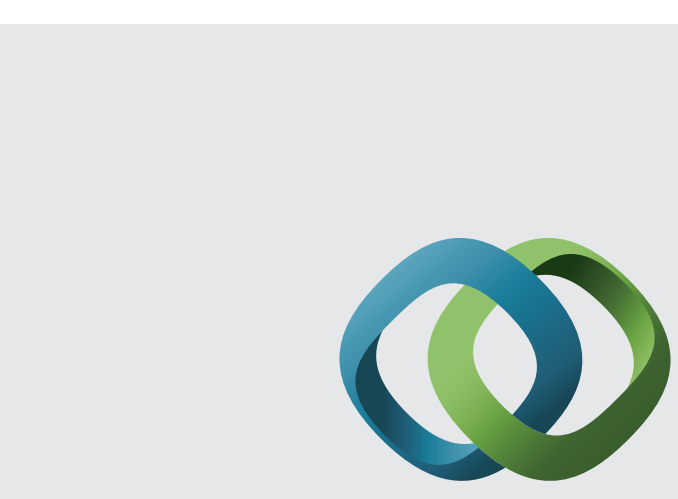

\section{Hindawi}

Submit your manuscripts at

http://www.hindawi.com
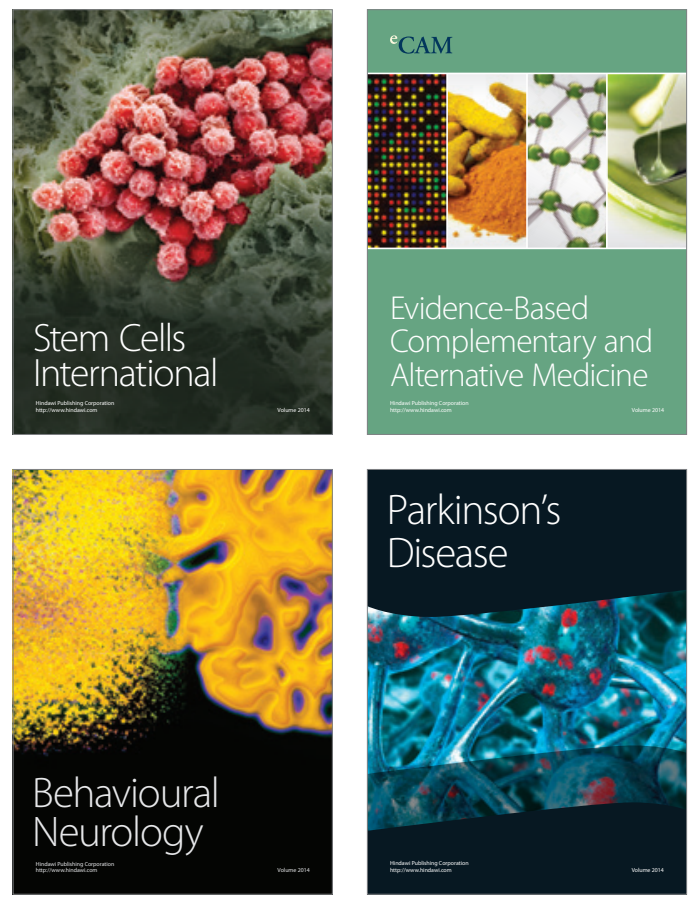
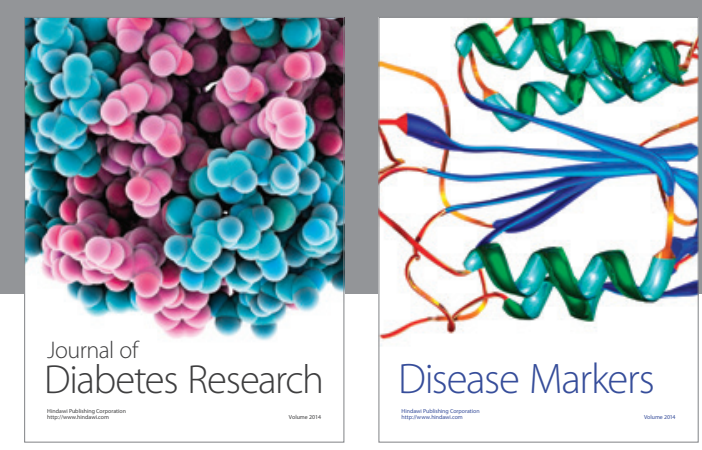

Disease Markers
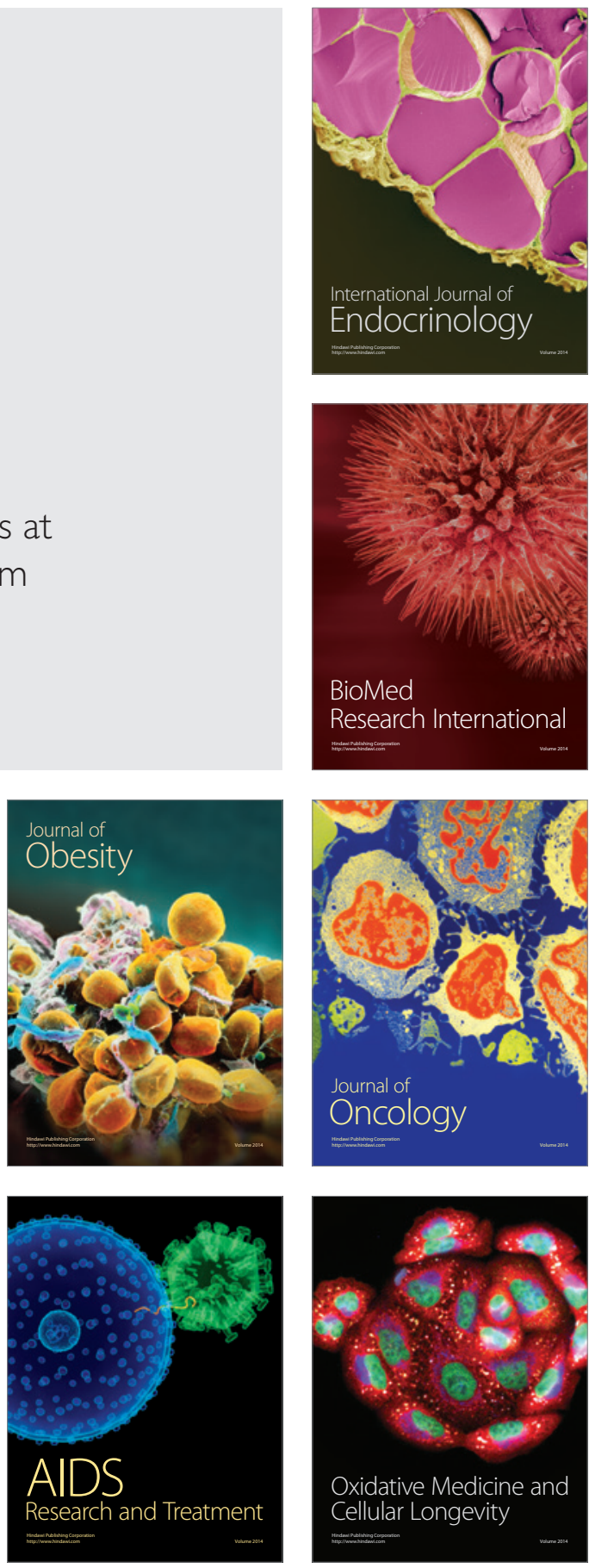